\title{
Coastally Trapped Wind Reversals: Progress toward Understanding
}

\author{
Wendell A. Nuss, ${ }^{*}$ John M. Bane, ${ }^{+}$William T. Thompson, ${ }^{*}$ \\ Teddy Holt," Clive E. Dorman,@ F. Martin Ralph, \& Richard Rotunno,** \\ Joseph B. Klemp,** William C. Skamarock,** Roger M. Samelson,++ \\ Audrey M. Rogerson,"\# Chris Reason, $@$ and Peter Jackson \&\&
}

\begin{abstract}
Coastally trapped wind reversals along the U.S. west coast, which are often accompanied by a northward surge of fog or stratus, are an important warm-season forecast problem due to their impact on coastal maritime activities and airport operations. Previous studies identified several possible dynamic mechanisms that could be responsible for producing these events, yet observational and modeling limitations at the time left these competing interpretations open for debate. In an effort to improve our physical understanding, and ultimately the prediction, of these events, the Office of Naval Research sponsored an Accelerated Research Initiative in Coastal Meteorology during the years 1993-98 to study these and other related coastal meteorological phenomena. This effort included two field programs to study coastally trapped disturbances as well as numerous modeling studies to explore key dynamic mechanisms. This paper describes the various efforts that occurred under this program to provide an advancement in our understanding of these disturbances. While not all issues have been solved, the synoptic and mesoscale aspects of these events are considerably better understood.
\end{abstract}

*Department of Meteorology, Naval Postgraduate School, Monterey, California.

+Marine Sciences Program, University of North Carolina, Chapel Hill, North Carolina.

"Naval Research Laboratory, Monterey, California.

${ }^{\circledR}$ Coastal Studies Program, Scripps Institution of Oceanography, University of California, San Diego, La Jolla, California.

\&NOAA/ERL/Environmental Technology Laboratory, Boulder, Colorado.

**National Center for Atmospheric Research, Boulder, Colorado.

${ }^{++}$College of Oceanic and Atmospheric Sciences, Oregon State University, Corvallis, Oregon.

\#\# Woods Hole Oceanographic Institute, Woods Hole, Massachusetts.

${ }^{\circledR}$ School of Earth Sciences, University of Melbourne, Parkville, Victoria, Australia.

${ }^{\&}$ Environmental Studies Program, University of Northern British Columbia, Prince George, British Columbia, Canada.

Corresponding author address: Dr. Wendell A. Nuss, Department of Meteorology, Naval Postgraduate School, 589 Dyer Road, Room 254, Monterey, CA 93943-5114.

E-mail: nuss@nps.navy.mil

In final form 9 September 1999

(C)2000 American Meteorological Society

\section{Introduction}

Several times each warm season the predominantly northerly winds off the U.S. west coast are interrupted by a period of southerly winds, caused by the northward propagation of a coastally trapped disturbance. These disturbances, which we will refer to here as coastally trapped wind reversals (CTWRs) and which are often called "southerly surges," typically last from one to several days and can spread coastal fog rapidly along several hundreds of kilometers of the coast (Fig. 1). Although the weather associated with CTWRs is rather benign compared to winter storms or tropical cyclones, the rapid transition from clear to foggy conditions severely limits air traffic at coastal airports (like San Francisco), surprises fishermen and recreational boaters so that they cannot easily navigate visually, and generally produces a chilly day for coastal inhabitants and beach users. Physically, CTWRs typically cause an abrupt change in the wind stress on the ocean's surface, variations in the oceanic surface wave field, changes in the structure of the marine atmospheric boundary layer, and the rapid spreading of 

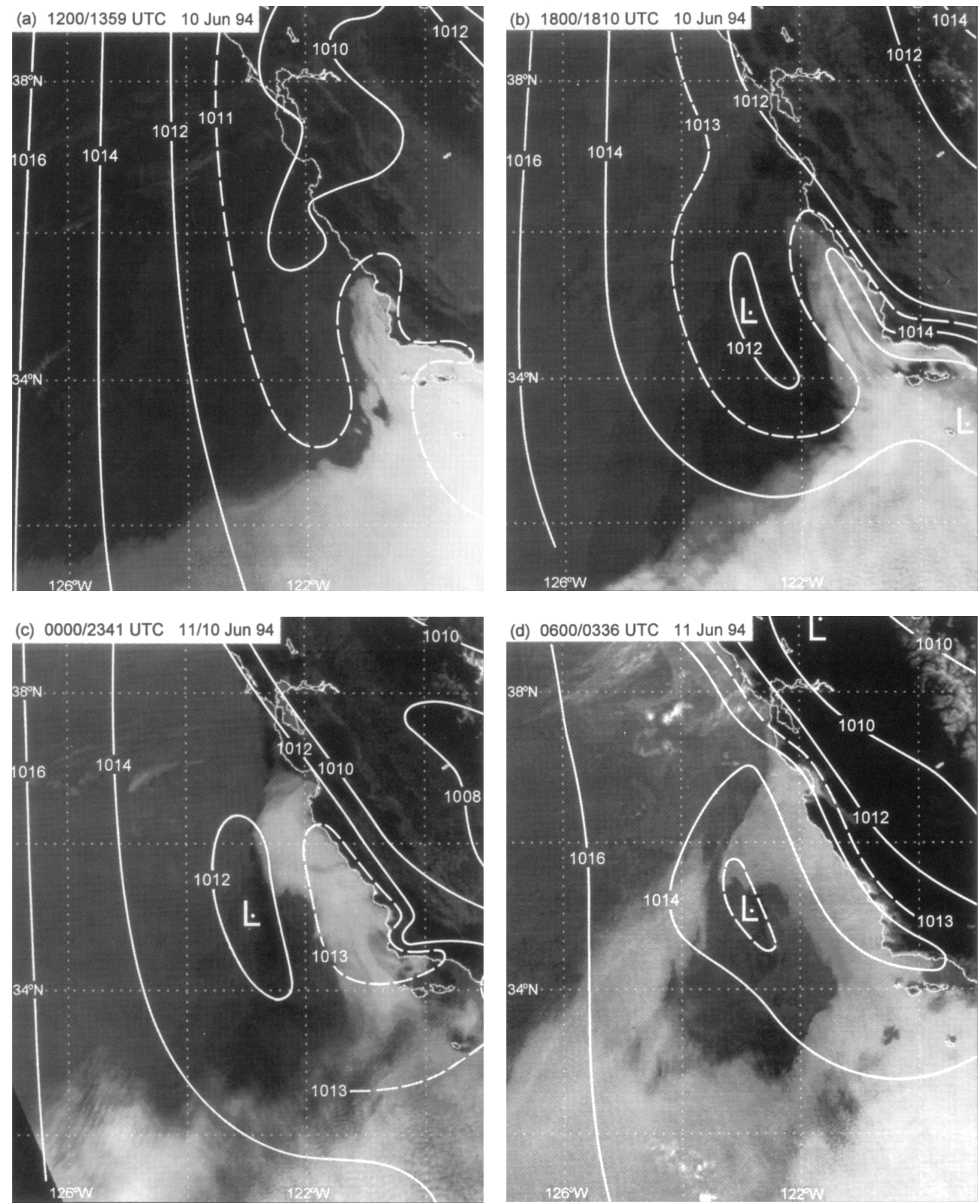

FIG. 1. Sequence of visible satellite images from a NOAA polar-orbiting satellite at (a) 1359, (b) 1810, and (c) 2341 UTC 10 Jun 1994, and infrared image from the same satellite at (d) 0336 UTC 11 Jun. Mesoscale sea level pressure (mb) analyses from the closest time are superimposed on each image. The time of each pressure analysis is shown followed by the time of each image. From Ralph et al. (1998). 
coastal fog. In addition to these impacts on the weather, these wind reversals disrupt the normal forcing of ocean upwelling which impacts on the ocean productivity. While the climatological synoptic-scale aspects of CTWRs are relatively well defined (Mass and Bond 1996, hereinafter MB96), forecasting these disturbances remains difficult, in part because the structure and governing dynamics of CTWRs are not completely understood.

Through its Accelerated Research Initiative (ARI) on Coastal Meteorology, the Office of Naval Research (ONR) has sponsored a broad research effort to examine the interaction of the coastal atmosphere with coastal topography under a variety of circumstances. The initiation, propagation, evolution, and decay of CTWRs were the subjects of the Experiment on Coastally Trapped Disturbances (ECTD), which was supported principally by the ONR Coastal Meteorology ARI. The general problem of the interaction of the marine atmospheric boundary layer with coastal topography was the primary focus of the Coastal Waves 1996 effort, which was also partially supported by the Coastal Meteorology ARI and is described by Rogers et al. (1998). The observational activities of Coastal Waves 1996 and those of the ECTD were complementary and partially concurrent in their execution. The interaction of winter fronts and cyclones with coastal topography was the primary focus of the Coastal Observation And Simulation with Topography (COAST) program, which was also partially supported under the Coastal Meteorology ARI and is described in Bond et al. (1997).

This paper describes the early results and some highlights of the ECTD. The scientific background and significant outstanding issues about CTWRs are described in sections 2 and 3. Sections 4, 5, and 6 summarize the observational and modeling efforts brought together to address the hypotheses embodied in the outstanding issues. The new understanding gained from the ECTD is described in section 7. In section 8 a summary is given and the remaining scientific questions are discussed. Much of this work is on going and will be or has been presented in other scientific articles; the intent here is to provide a broader scientific perspective within which the specific ECTD studies fit.

\section{Scientific background}

CTWRs represent significant departures from the typical warm season, low-level airflow along the west coast of the United States. The typical pattern is dominated by the North Pacific anticyclone, which produces northerly winds and a strong low-level temperature inversion due to the associated large-scale subsidence that traps a cool layer of air adjacent to the cold, underlying ocean water. This cool "marine layer" is composed of a mixed layer capped by the marine layer inversion. The mixed layer usually extends upward from the ocean surface for several hundred meters, and the overlying marine layer inversion, in which the in situ temperature increases with height, can vary from tens to hundreds of meters in thickness (Nieberger et al. 1961). The top of the marine layer (i.e., the top of the inversion) is generally below the $300-800-\mathrm{m}$ tops of the mountains that are present along almost this entire coastline. The mountains keep the cool, dense marine layer air from flowing over the adjacent land mass, and the highly stratified coastal air mass thus forms a layered fluid system bounded on one side by the mountains. This system can support several classes of air motions that are not possible when either the low-level stratification or the coastal mountain barrier (or both) is absent.

CTWRs compose one class of airflow event that occurs in the stratified coastal marine atmosphere off the U.S. west coast. The northward airflow in a CTWR is forced to flow along the coastal mountains by the Coriolis effect, and the resulting winds are trapped within about $100 \mathrm{~km}$ of the coastline, a distance roughly equal to the baroclinic radius of deformation in this system. To support the southerly wind along the coast, the local, along-coast pressure gradient force must be oriented from south to north. Controversy has surrounded the mechanisms that produce this reversal in the pressure gradient force from its more typical north-to-south orientation.

Prior to 1996, case studies of a few individual CTWRs gave inconsistent views of the synoptic-scale evolution associated with these events. MB96 have helped to rectify this by constructing composites for the synoptic- to large-scale evolution associated with 47 CTWR events. Their study has shown that a rather characteristic evolution can be associated with CTWRs. The pattern typical of the initiation phase of a CTWR along the central California coast is shown in Fig. 2. The 500-mb analysis shows ridging just off the West Coast, which progresses eastward as the CTWR evolves. The sea level pressure analysis shows that the inland thermal trough tends to shift toward the coast or just offshore in northern California to weaken or reverse the nominal southward along-coast pressure 


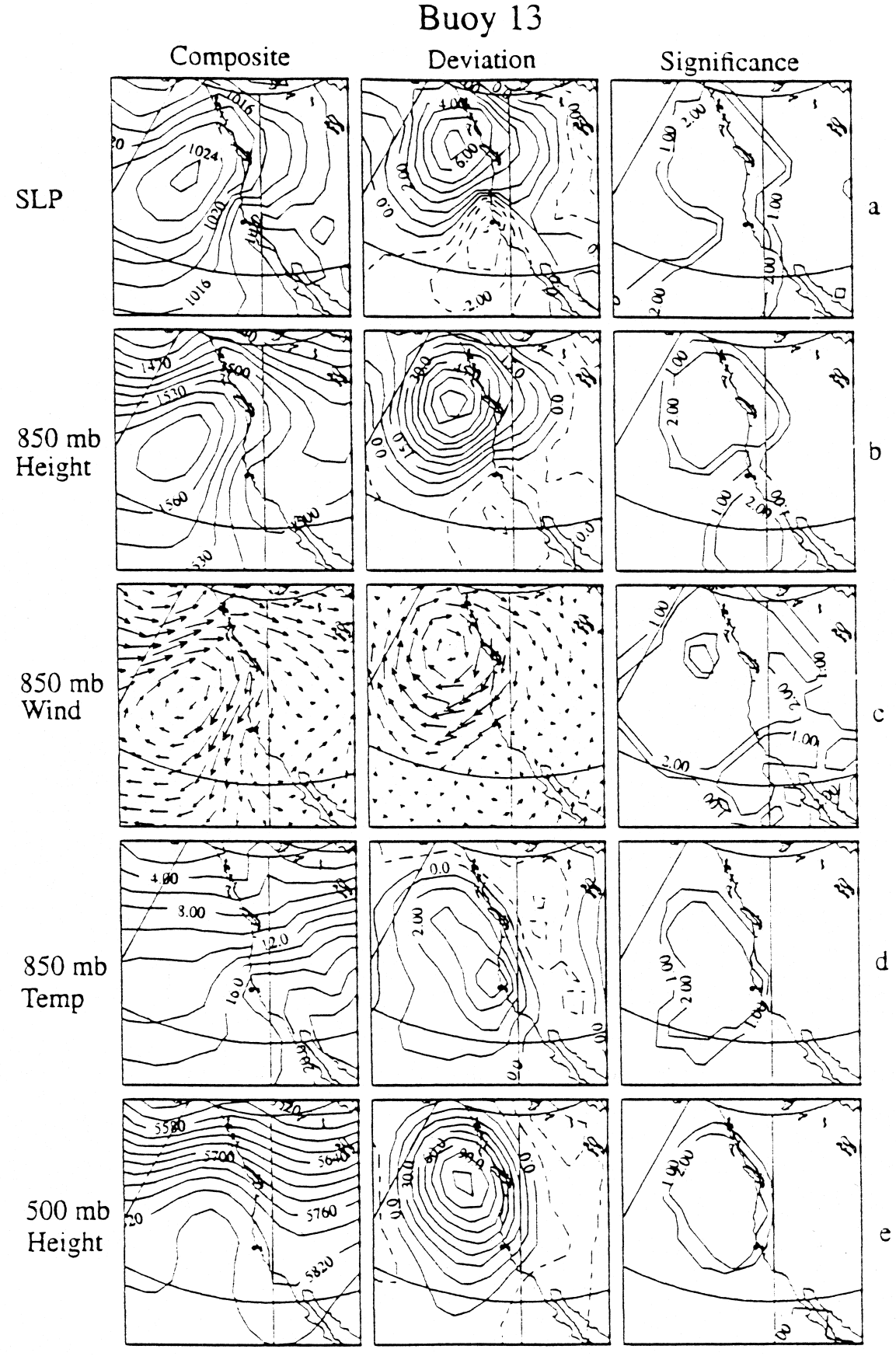

FIG. 2. Composites, deviations from climatology, and the significance of the deviations for the times of strong wind reversals at buoy 46013. The maximum composite and deviation wind vectors are 12.6 and $9.4 \mathrm{~m} \mathrm{~s}^{-1}$, respectively. In the significance figures, the $95 \%$ and $99 \%$ significance levels are indicated by the 1.00 and 2.00 , respectively. The location of buoy 46013 is indicated by the black dot. From Mass and Bond (1996). 48-h evolution of the synoptic environment just preceding the initiation of a representative CTWR is shown in Fig. 3, where the inland movement of a highpressure ridge into Washington and Oregon, and the northwestward extension of the inland thermal trough in California are seen (Ralph et al. 1998). In addition, Fig. 3 highlights the existence of a region of 24-h surface pressure falls, and changes in the position and strength of the northerly coastal jet. The position of the surface pressure change pattern and its northward movement are consistent with the northward movement and acceleration of the northerly coastal jet, just north of the center of the region of pressure falls. While these synoptic patterns are quite pronounced in many CTWR cases, there is considerable case-to-case variability, which was not addressed by MB96. In addition, the characteristic synoptic pressure pattern does not always produce a CTWR, which indicates that other factors play a role and can contribute to forecast uncertainty.

CTWRs have been interpreted in three different ways: as freely propagating Kelvin waves (Dorman 1985, 1988), as topographically trapped density currents (Dorman 1987; Mass and Albright 1987), and as the mesoscale response to the alongshore pressure gradients produced by the orography and the synoptic scale flow (Mass et al. 1986; Mass and Albright 1988;

gradient force, to the south of the thermal trough. This shift in the position of the surface trough is associated with warm temperature and offshore directed flow near $850 \mathrm{mb}$, suggesting that troughing in the lee of the coastal mountains and/or offshore advection of warm continental air is responsible for the warming. The
MB96). The theoretical study by Reason and Steyn (1992) suggests that both marine layer processes (Kelvin wave or gravity current dynamics) and synoptic-scale processes contribute to the initiation and evolution of CTWRs, which indicates that simplified interpretations based on a single process may be 

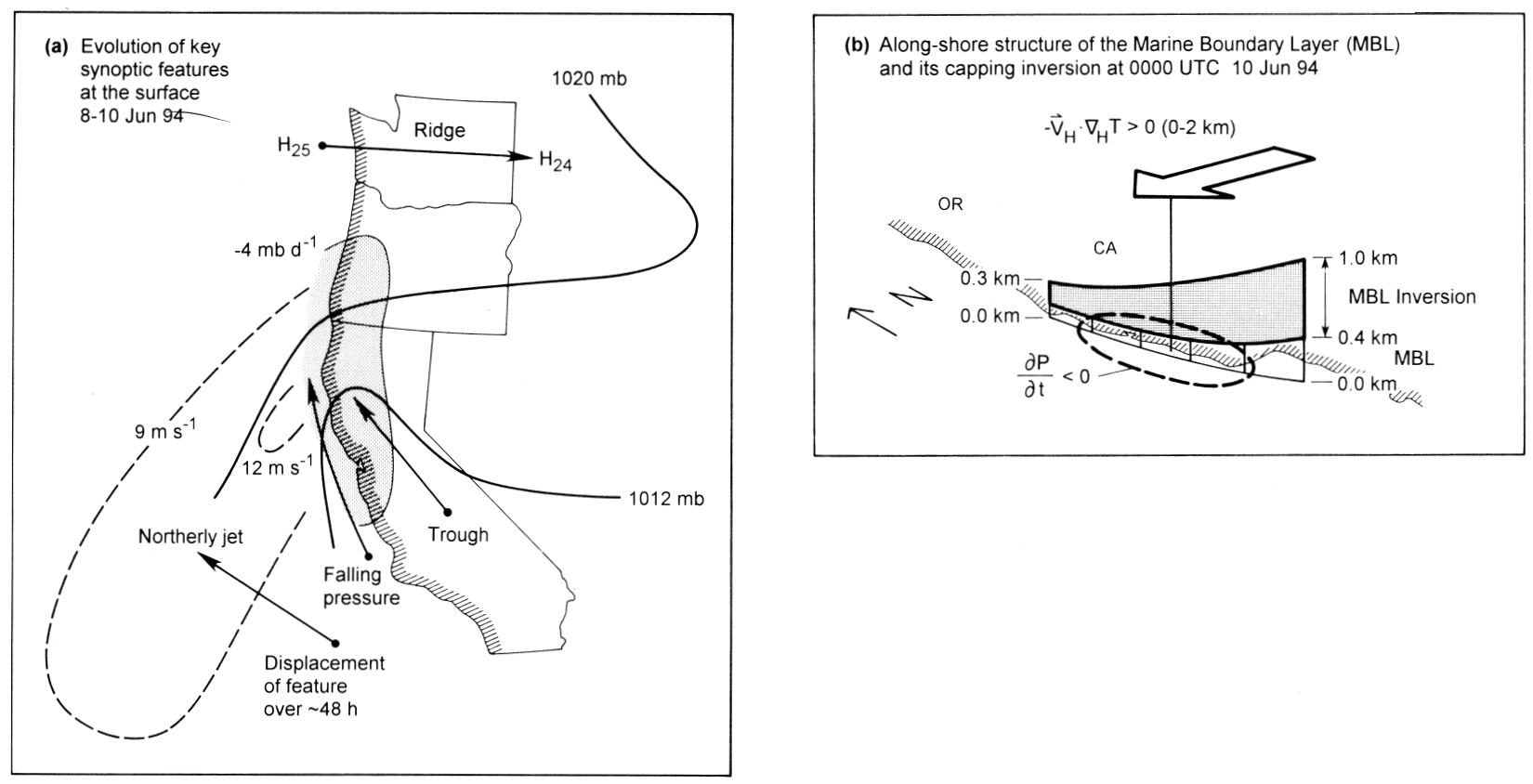

FIG. 3. (a) Synoptic overview of the preconditioning before southerly alongshore flow developed. Arrows and dashed lines represent the movement over approximately $48 \mathrm{~h}$ of the feature at the end of the arrow. (b) Vertical structure of the MBL inversion, and the relationship between the region of coastal pressure falls and lower-tropospheric warm advection. From Ralph et al. (1998).

inadequate. Even though CTWRs may contain components of all three processes, the individual interpretations regarding the governing dynamics have important implications about the structure, initiation, and propagation of coastally trapped disturbances, which provides the basis for the outstanding issues presented in the next section.

The Kelvin wave interpretation is based on the idea that the atmosphere along the U.S. west coast during the summer months can be approximated as a twolayer system with the topography providing a wall along the eastern boundary of the fluid. A propagating, wavelike disturbance can be excited along the coast if the top of the marine layer is lifted or depressed along some portion of the coast. This can produce a northward moving Kelvin wave (depicted schematically in Fig. 4a) that will produce a signature in the surface pressure field due to the thickness variations of the marine layer. Linear theory, applied to a case examined by Dorman (1985), predicts a uniform propagation speed of about $6 \mathrm{~m} \mathrm{~s}^{-1}$ for that case. This uniform $6 \mathrm{~m} \mathrm{~s}^{-1}$ propagation agrees with some observations but disagrees with the nonuniform propagation characteristics observed for many disturbances (Bond et al. 1996; Ralph et al. 1998). These variations in propagation have been hypothesized to be the result of nonlinear dynamics, topographic gaps, bends in the coastline, and/or diurnal effects. The initiation of a Kelvin wave has not been fully explained theo-


FIG. 4. Sketch of idealized structure of a coastally trapped (a) Kelvin wave and (b) gravity current. 
retically nor observed, although recent modeling efforts by Samelson and Rogerson (1996) and Skamarock et al. (1999) have provided important insight into possible initiation mechanisms. These studies are described further in section 6 .

The gravity current or internal bore interpretation is based on the idea that a thick, cool marine layer often exists to the south along the coast with little or no marine layer farther north. Under these conditions, the cool air in the thicker marine layer acts as a source of more dense fluid that subsequently flows northward to push the less dense air out of the way (Fig. 4b). The signature in the surface pressure field is again due to marine layer thickness differences that occur across the leading edge of the gravity current. Nonuniform propagation may be the result of along-coast variations in the environmental fluid characteristics and/ or diurnal variations. The hypothesized scenario for the initiation of the gravity current is for the marine layer to be substantially reduced in thickness to the north due to the passage of a synoptic-scale system. The thicker reservoir of cool air to the south is then released by some unknown event to begin the flow of marine layer air northward. The initiation mechanism has not been previously identified in the literature, although the modeling work by Jackson and Reason (1995), described in section 6, has examined the evolution of these types of disturbances under realistic synoptic-scale structures.

The Kelvin wave and gravity current interpretations both rely on marine layer thickness variations to generate the pressure gradients that support propagation, but differ in several clearly identifiable ways. First, the Kelvin wave represents a wavelike disturbance along a relatively uniform marine layer, while the gravity current represents a distinct discontinuity in the marine layer thickness. (An internal bore, i.e., a generalized gravity current with an elevated discontinuity in the marine layer thickness, is also possible, and the thickness change at the leading edge of the bore is considerably more abrupt than that of a Kelvin wave.) Next, the gravity current leading edge is characterized by considerable small-scale vertical motion that does not occur with a Kelvin wave, as suggested schematically in Fig. 4. Finally, the rapid change in marine layer thickness across the gravity current leading edge will tend to produce air mass differences (e.g., different equivalent potential temperatures) across the gravity current leading edge. The nonturbulent gradual changes associated with the Kelvin wave will not produce an appreciable equivalent potential temperature difference across the leading edge of the wave. Klemp et al. (1997) show that the internal bore also has no appreciable equivalent potential temperature gradient at the surface and has a dynamic evolution characteristic of a gravity current, which the internal bore becomes in the limit of the marine layer depth going to zero ahead of the bore. Consequently, the equivalent potential temperature near the surface is not sufficient to distinguish between these types of disturbances. The results of Bond et al. (1996) show that the temperature changes observed at most of the coastal buoys are very small as the disturbance passes; the exceptions are those buoys farther north along the Oregon and Washington coasts. This suggests that the gravity current explanation may not be correct for the CTWRs along the California coast but may be more applicable to CTWRs farther north.

The interpretation of a CTWR as a mesoscale response to the along-coast pressure gradient is based on the idea that orographic and synoptic-scale flow variations along the coast produce mesoscale, alongcoast pressure gradients that cause southerly winds on some portion of the coast. The basic idea is that as the MB96 synoptic-scale pattern evolves, a region of relatively strong offshore directed flow develops along some portion of the coast and produces a mesoscale lee trough. The amplitude of the lee trough is dependent upon the strength and stability of the synopticscale flow, both of which may vary along the coast. Propagation of the lee trough to the north results from the shift of the subtropical high to the north and east over time. Consequently, the largest negative perturbation pressure propagates northward, and a zone of southerlies is observed to the south of this feature. In this case the propagation speed depends upon the movement of the synoptic-scale features, which is likely to vary from one event to the next. Differential propagation speeds and abrupt transitions along large portions of the coast are easily accounted for in this interpretation.

The MB96 synoptic patterns are consistent with all three CTWR interpretations and do not allow a distinction to be made between the dynamical processes that actually drive a particular CTWR event. Fundamentally, the distinction between these various processes rests on the role that marine layer thickness variations play in the CTWR. The mesoscale response interpretation suggests that the marine layer thickness variations are unimportant and only an artifact of the CTWR, not the forcing mechanism. The Kelvin wave and gravity current interpretations rely primarily on 
marine layer thickness differences to force the CTWR as long as the synoptic-scale environment is favorable. A favorable synoptic environment consists of a south to north pressure gradient along the coast, which occurs in virtually all events examined by MB96 (Mass and Bond 1997). However due to analysis resolution differences, the coastal alongshore pressure gradient may not always appear favorable as suggested by Dorman (1997). Some of this subtlety in the alongcoast, sea level pressure gradient may be the pressure effect due to the alongshore thickness change of the marine layer (order 2-3 hPa) (Dorman 1997), which may not be fully represented in synoptic analyses based on limited coastal observations. The important question is whether the resultant alongshore pressure gradient in a given situation is due primarily to the large-scale processes above the marine layer or to the marine layer thickness variations themselves. These differences may explain why CTWRs do not occur in some cases even though the larger-scale pressure gradient is favorable.

\section{Summary of outstanding issues}

As highlighted in the previous section, crucial gaps in our understanding of CTWRs have lead to differing and sometimes contradictory explanations of this phenomenon. A number of specific hypotheses were laid out in preparation for the ECTD, and they are described in detail in Nuss (1996). These hypotheses reflect the important outstanding issues surrounding the CTWRs, which can be summarized as follows.

1) What are the relative roles of marine layer thickness variations along the coast versus synopticscale (above the marine layer) pressure gradients in setting up a northward alongshore pressure gradient force and southerly winds?

2) Can CTWR internal dynamics be clearly characterized as either Kelvin wave, gravity current, internal bore, or ageostrophic mesoscale flow due to the synoptic-scale pressure gradient?

3) What are the specific characteristics of the synoptic-scale flow that respond to the coastal topography to spawn either a Kelvin wave, gravity current, internal bore, or coastally trapped ageostrophic flow?

4) What are the important mechanisms that lead to uneven propagation and to the decay of these disturbances?
5) What processes lead to the cloud layer that typically progresses northward with the southerly winds?

To help address these issues, both modeling and observational studies were undertaken prior to and within the ECTD.

\section{ECTD observational activities}

\section{a. Background synoptic-scale studies}

The propagating nature of a CTWR is not easily explained from the MB96 perspective. Also, their study utilized very coarse resolution synoptic analyses. In preparation for the ECTD field program and to provide higher resolution descriptions than found in MB96, Nuss (1998) examined a broad range of CTWRs, excluding "synoptic events" as defined by Bond et al. (1996), that occurred between 1994 and 1996. The synoptic-scale characteristics were defined using the National Centers of Environmental Prediction (NCEP) Eta Model analyses and then related to the propagation character of the disturbance. The propagation characteristics were defined by tracking the northward progress of the wind reversal for 16 CTWRs. Although propagation was difficult to define absolutely, there was a clear difference between CTWRs that tend to progress up the coast and those where the wind shifts occurred more uniformly along the coast. These differing propagation characteristics were tied to the synoptic scale structure. A key finding is that persistent, low-level, offshore flow is required to obtain a propagating disturbance, which can be seen in a comparison of the cross-coast wind component shown in Fig. 5. The wind can reverse in an apparent CTWR due to the lowering of the pressure along the coast to the north. This pressure decrease can result from a variety of subtly different synoptic flow patterns, including the MB96 pattern as well as much stronger synoptic events, which were excluded by both MB96 and Nuss (1998). However, without persistent offshore flow over a broad region of the coast, the wind reversal fails to propagate. These results suggest a strong tie between the mesoscale coastal response, the CTWR, and the character of the synoptic-scale forcing. It appears that a Kelvin-wave-like CTWR may only occur under certain types of persistent offshore flow and is consistent with Reason and Jury (1990), which showed Kelvin wave disturbances occurred when a reduced-gravity model was forced by persis- 


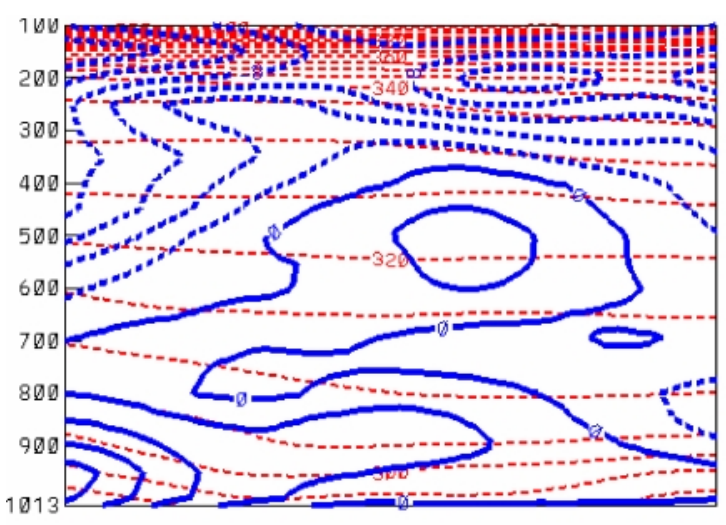

(A)



(B)

FIG. 5. Composite cross sections of the potential temperature (K) (dashed) and cross-coast wind component (m/s) (solid/dashed) for (a) propagating and (b) nonpropagating CTWRs at buoy 46028.

tent warm, offshore flow. This remains to be firmly established, though, as there were only a limited number of cases (four) observed during the ECTD with sufficient coverage and resolution to describe the mesoscale CTWR structure (see section 5 below).

\section{b. The 1994 and 1996 field programs}

ECTD field programs were conducted during 1994 and 1996, and these efforts resulted in the direct measurement of four CTWR events along the California/ Oregon coast. A short duration field program was executed in 1994, and a several-month-long field program in 1996. During both years, measurements were made from coastal meteorological stations, coastal and inland wind profilers, moored and free-drifting offshore buoys, satellites, and an instrumented aircraft. Four CTWRs were measured in greater detail than any previous CTWR events, and these observations have provided new insight into the structure and life history of this phenomenon.
During both years, the standard surface and upper air observing network was enhanced with coastal wind profilers, surface stations, drifting buoys, and additional rawinsonde launches from cooperating Department of Defense sites. This surface and upper air observing network is shown in Fig. 6. The coastal wind profilers were $915-\mathrm{MHz}$ profilers operated by the National Oceanic and Atmospheric Administration (NOAA) Environmental Technology Laboratory and the Naval Postgraduate School (NPS) to provide boundary layer winds and RASS-derived virtual temperature profiles on at least an hourly basis. Wind and temperature data were generally available at 60 - or 100-m vertical spacing from $100 \mathrm{~m}$ AGL to $1-3 \mathrm{~km}$ AGL. In both 1994 and 1996, a Minerals Management Service-sponsored program supported measurements from a network of fixed surface observing stations in the Santa Barbara Channel as well as farther north



FIG. 6. Observing sites for surface (METAR sites solid dots, moored buoys small solid squares, drifting buoys triangles), sounding (large stars), and profilers (large squares) taken during the summer of 1996. 


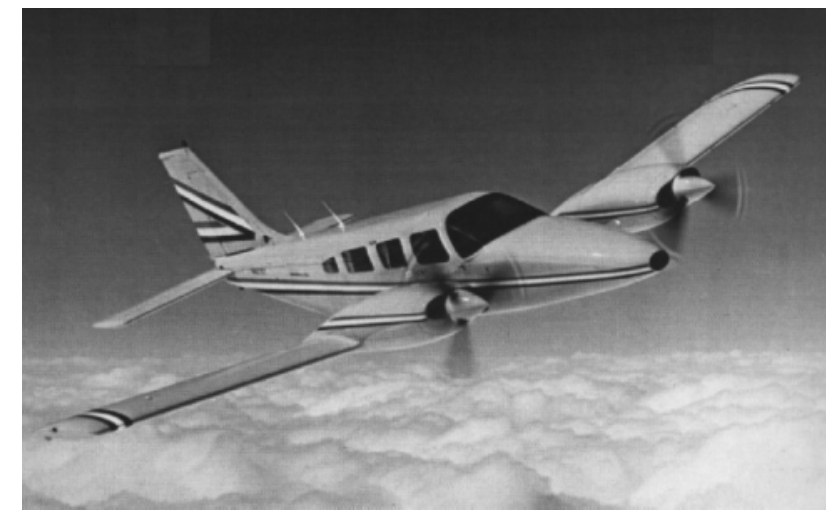

FIG. 7. Piper Seneca III light twin-engined aircraft instrumented and operated by the University of North Carolina at Chapel Hill.

along the coast. At several locations these were deployed in pairs, one at about sea level, and one several hundred meters up the coastal mountain slope. Drifting buoys, of the Surface Velocity Program barometric type, were deployed in both years to enhance surface temperature and pressuremeasurements offshore. These buoys were drogued to drift with the 15$\mathrm{m}$ current, which carried them south along the coast at a rate of about $15 \mathrm{~km} \mathrm{day}^{-1}$. Due to this southward advection by the California current, the buoy array was reseeded once during the summer 1996 field program.

Detailed, overwater sampling of infrequent, shortlived events such as CTWRs also requires a measurement capability that is available on short notice (typically a day or two in advance of CTWR initiation), can follow the events over several days and hundreds of kilometers along the coast, and can provide in situ measurements over the three-dimensional volume of the air mass involved in the event. For the ECTD, a light aircraft was instrumented to measure horizontal wind, temperature, humidity, and pressure at a 1-Hz sampling rate (Fig. 7). This aircraft, a Piper Seneca III operated by the University of North Carolina at Chapel Hill (UNC-CH), was available exclusively to the ECTD during the field studies of 1994 and 1996, and it proved invaluable in obtaining data on the structure and evolution of the four CTWRs that occurred during the field studies. The Piper Seneca aircraft is an all-metal, low-wing, nonpressurized, twinengined platform with a range of about $1400 \mathrm{~km}$ and an altitude ceiling up to $7600 \mathrm{~m}$. Air temperature, relative humidity, pressure, and radar altitude are measured directly, while the indicated airspeed, aircraft heading, and GPS location are used to derive the winds to an accuracy of about 1-2 $\mathrm{m} \mathrm{s}^{-1}$. Complete descriptions of the aircraft, its sensors, and data system are given in Bane et al. (1995) and Bane (1997). Seven research flights were flown during 1994 and 33 research and two calibration flights were flown during 1996 (Fig. 8).

\section{c. Related programs}

Other research programs also took place along California during 1994 an 1996, which enhanced the spatial coverage of measurements and provided a synergistic advantage to all. During 1994, the Monterey Area Ship Tracks Experiment (Durkee et al. 2000) was conducted using primarily instrumented aircraft to study ship-generated cloud trails and atmospheric boundary layer processes off central California in the general vicinity of Monterey. During 1996, the Coastal Waves Program (Rogers et al. 1998) utilized the National Center for Atmospheric Research (NCAR) C-130 aircraft and the UNC-CH Piper Seneca aircraft to study a variety of coastal meteorological phenomena along the California coast.

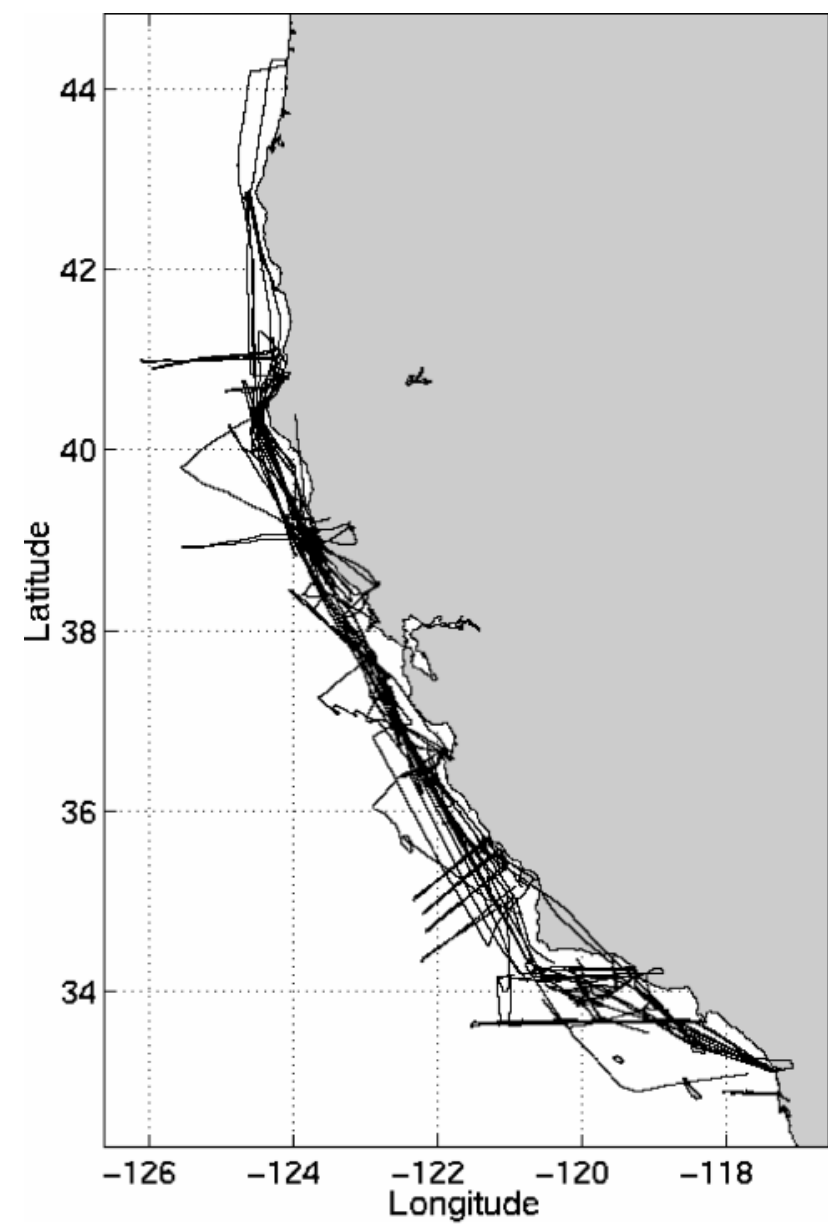

FIG. 8. Flight lines flown by the UNC Piper Seneca aircraft during the ECTD. 


\section{Case studies during the ECTD}

Prior to the observations taken in the ECTD, detailed CTWR structure could only be inferred from high temporal resolution coastal observations and satellite cloud imagery. As discussed above, previous studies have described structures that resemble either a gravity current or Kelvin wave, in which the marine layer undergoes an abrupt or gradual thickening as the disturbance passes. An example of the passage of a CTWR at a coastal site near Monterey Bay is given in Fig. 9, which illustrates both the impact of the CTWR on the marine layer as well as the complexity of diagnosing the structure of a CTWR from a single coastal site. In this event, the NPS 915-MHz profiler and radio acoustic sounding system (RASS) show a sharp transition at 0000 UTC 11 June 1994. The strong cooling and wind shift in the lowest $300 \mathrm{~m}$ looks remarkably similar to what a CTWR should look like based on the hypotheses in earlier studies. However, similar transitions occurred at the same times on the two preceding days, which mark the onset of the diurnallydriven sea breeze under conditions of offshore flow. The persistent 300-500-m deep marine layer after the passage of the CTWR late on 10 June signifies the impact of its passage on the nearshore atmosphere, even though the detailed structure of the disturbance is not completely evident. Several studies during the ECTD have explored this case in great detail and have aided in our understanding of CTWRs (Thompson et al. 1997; Dorman et al. 1998; Ralph et al. 1998, 2000) including the surprising result that the CTWR perturbation is focused in the inversion capping the marine boundary layer (MBL) with little MBL depth change itself. Three additional CTWRs were observed in the 1996 ECTD field program. Of these four CTWR cases, two were observed off central California (10-11 June 1994 and 5 June 1996; we refer to these as the "southern cases"), and two were observed off northern California/southern Oregon (21-22 July and


FIG. 9. (a) Time-height section of hourly RASS virtual potential temperature (K, solid), and hourly consensus horizontal winds, from the Naval Postgraduate School (NPS) 915-MHz radar wind profiler between 0000 UTC 8 Jun 1994 and 0000 UTC 13 Jun 1994. Hourly averaged surface winds measured at the profiler site are included. Wind barbs are in Kt and northerly direction points to bottom of plot. For clarity, only every other wind profile is shown. Gaps in profiler wind data are from interference due to a nearby airport surveillance radar. (b) Surface data from NPS, including observed $\left(P_{\mathrm{obs}}\right)$, temperature $\left(T_{\mathrm{obs}}\right)$, dewpoint temperature $\left(T_{\mathrm{d} \text {, obs }}\right)$, and surface pressure calculated hydrostatically from RASS $T_{v}$ profiles below $1.5-\mathrm{km}$ altitude $\left(P_{\text {calc }}\right)$. From Ralph et al. (1998a).
1-2 September 1996; we refer to these as the "northern cases"). Provided in the next subsections are observations, primarily from the aircraft and satellite imagery, showing the temperature, wind and cloud fields for two of these cases. The observed structure is compared with the Naval Research Laboratory's Coupled Ocean-Atmosphere Mesoscale Prediction System (COAMPS) (Hodur 1997) model simulations of these cases.

\section{a. The 10-11 June 1994 event}

Figures 1a-d show satellite images and corresponding sea level pressure analyses valid at about 1400 and 1800 UTC 10 June, and 0000 and 0330 UTC 11 June 1994, respectively. These images document the northward propagation of a "tongue" of stratus/fog along the coast associated with this CTWR. The sea level pressure analyses at the image times show the development of a weak mesoscale low offshore and a coastal pressure ridge. Figures 10d-f show 
COAMPS model forecast streamlines at $1000 \mathrm{mb}$ and cloud liquid water mixing ratio (shaded) at 0000 and 1400 UTC 10 June, and 0300 UTC 11 June (Thompson et al. 1997) along with the corresponding satellite images for comparison (Figs. 10a-c). In this case, southerly flow begins in the Southern California Bight around 0500 UTC 10 June. The southerlies pass Pt. Conception at 0900 UTC, arrive at Monterey Bay at 1600 UTC, and reach Pt. Reyes at 0700 UTC 11 June. These times were taken from Ralph et al. (1998) and
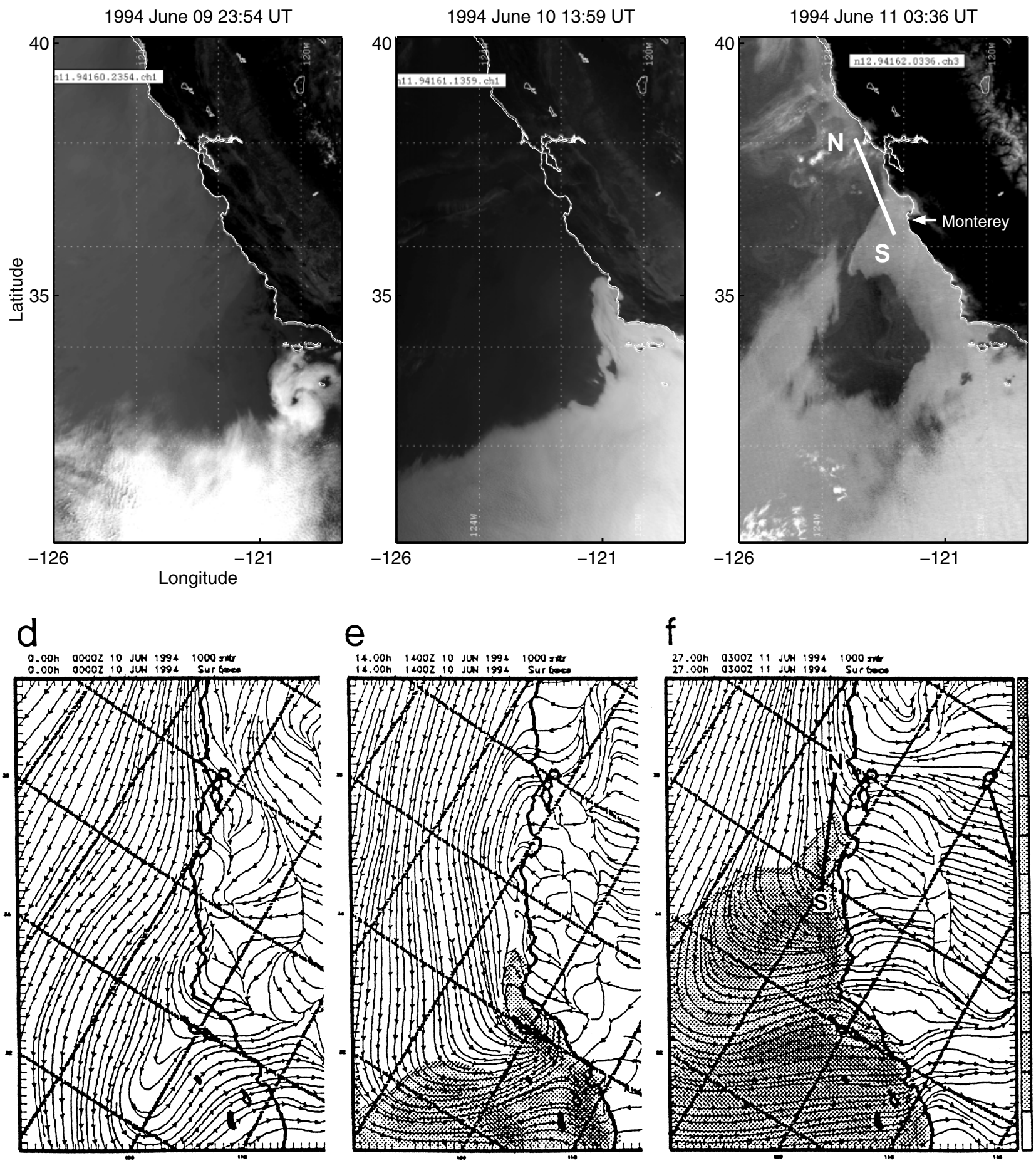

FIG. 10. GOES-9 visible satellite images valid at (a) 2354 UTC 9 Jun 1994, (b) 1359 UTC 10 Jun, and (c) 0336 UTC 11 Jun and COAMPS forecast 1000-mb streamlines and cloud liquid water (g/kg) (shaded) valid (d) 0000 UTC 10 Jun, (e) 1400 UTC 10 Jun, and (f) 0300 UTC 11 Jun. Cross-section planes are indicated in (c) and (f). From Thompson and Bane (1998). 
differ somewhat from those of the model forecast, although the model depicts a very consistent evolution. The coastal southerlies in this case are preceded by offshore flow along much of the coast (note the offshore flow between Pt. Sur and Pt. Conception in Fig. 10d), leading of a "heat wave" at coastal locations (the high temperature in San Francisco on 10 June, for example, was $36^{\circ} \mathrm{C}, 17^{\circ} \mathrm{C}$ above the monthly mean maximum temperature). In conjunction with the heat wave, the thermal trough, initially positioned over the central valley of California, is centered over the coast to the south of Monterey by 1200 UTC 10 June. Offshore flow extends vertically to above $700 \mathrm{mb}$. Ralph et al. (1998) show that warming due to westward horizontal advection in the offshore flow over the lowest $1.5 \mathrm{~km}$ results in lowering pressure all along the coast, with the lowest pressure initially just to the south of Monterey
Bay. The pressure minimum moves to the north with time, reaching Pt. Reyes by 1200 UTC 11 June.

Shown in Figs. 11a-d are vertical cross sections from the aircraft and from the model depicting potential temperature with cloud water (shaded) and wind speed in the plane of the cross section (i.e., the coastparallel wind component) with cloud water (shaded). The model panels are valid at 0300 UTC 11 June. The COAMPS simulations of this event are described in detail by Thompson et al. (1997). Comparison of Figs. 11a and 11c shows that the model has some of the same features of the observed temperature field and that the model clouds extend farther to the north than observed, although the low liquid water content near the leading edge of the model may not correspond to a visible "fog." The model thermal field suggests a deep, nearly neutral layer above the marine layer in-
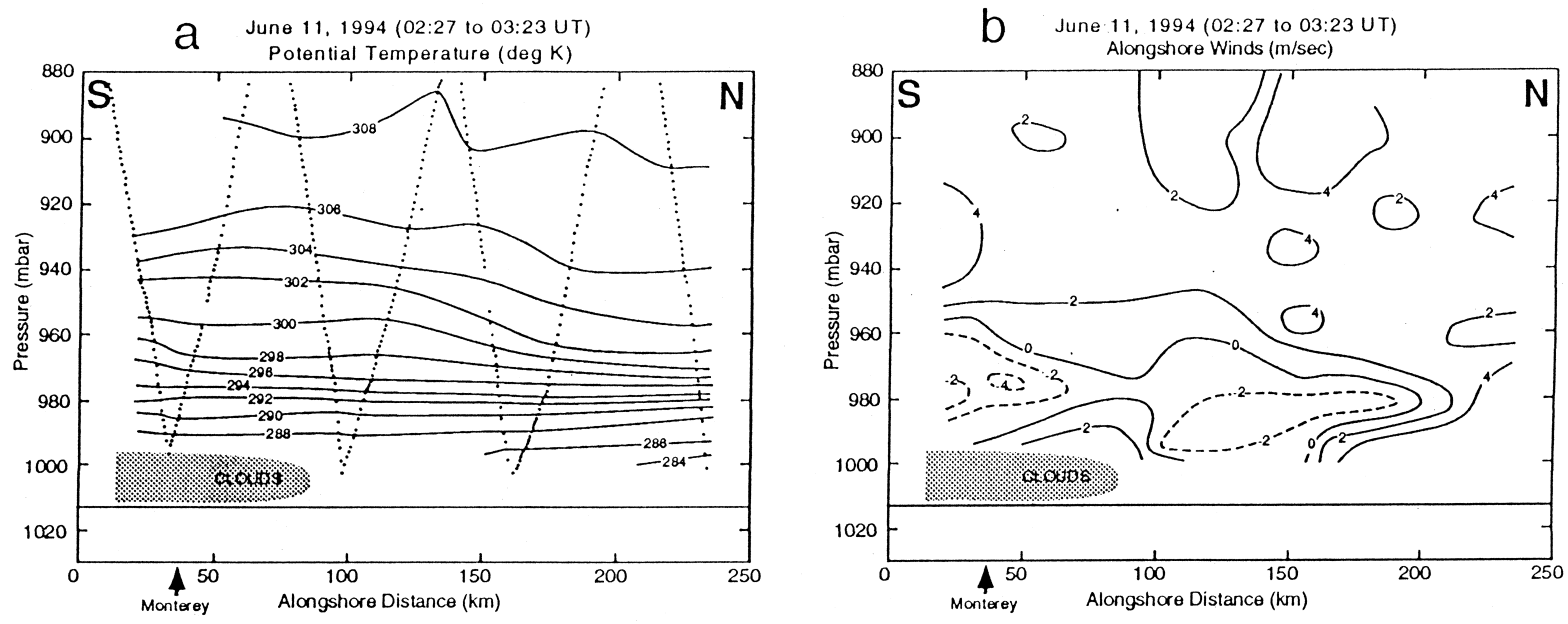

C
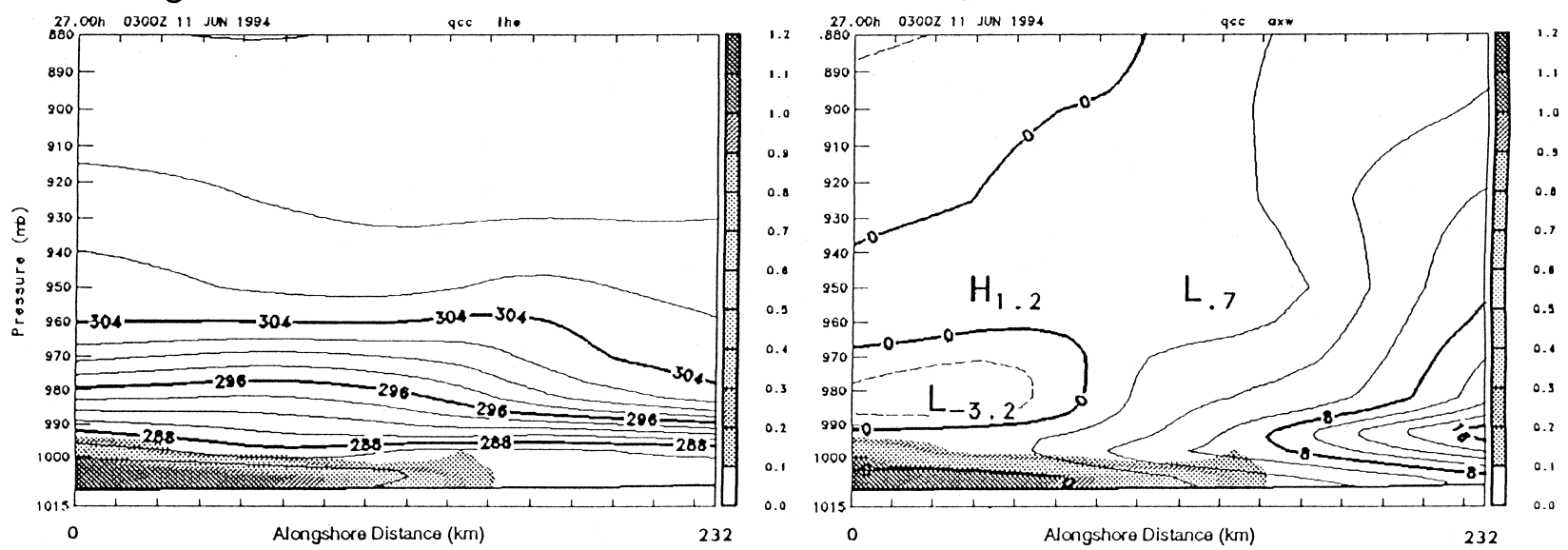

FIG. 11. Cross sections for 0300 UTC 11 Jun 1994 from the aircraft of (a) potential temperature (K) and cloud (shaded) and (b) wind speed in the plane of the cross section $\left(\mathrm{m} \mathrm{s}^{-1}\right.$ ) with cloud (shaded); and from the COAMPS model of (c) potential temperature with cloud liquid water mixing ratio $\left(\mathrm{g} / \mathrm{kg}\right.$ ) (shaded) and $(\mathrm{d})$ wind speed in the plane of the cross section ( $\mathrm{m} \mathrm{s}^{-1}$ ) with cloud liquid water mixing ratio (shaded). Southerly (coast-parallel) winds are dashed and northerly winds are solid. From Thompson and Bane (1998). 
version [this is a prominent feature of this case, as documented by Ralph et al. (1998) and Thompson et al. (1997)], some upward expansion of the inversion in the region of southerly flow in the model, and a strengthening of the inversion in the northerly flow to the north of the southerlies. Comparison of Figs. 11b and $11 \mathrm{~d}$ show some similar structures such as an elevated tongue of southerly flow at about the 980-mb level. However, the leading edge of these southerlies are some $100-150 \mathrm{~km}$ ahead of the leading edge of the near-surface cloud/fog in the observations but $50 \mathrm{~km}$ behind the model clouds. The model also produced much stronger northerlies ahead of these southerlies. Although this "intrusive" behavior of the southerlies came as a bit of a surprise, Ralph et al. (2000) have used the aircraft and buoy data from this event to establish, through comparison with the climatology of many events given by Bond et al. (1996), that this behavior may be representative of many CTWRs in the southern region. The structure is summarized in Fig. 12, where it is shown that the upward expansion of the MBL inversion causes cooling that initiates a weak $(0.4 \mathrm{mb})$ pressure rise at the surface. The beginning of this pressure rise also marks the beginning of a decrease in the alongshore northerly winds, which ultimately reverse sign at the surface about 3-4 h later. The weakness of this feature in the pressure field likely contributed to the difficulty in observing it in individual cases using standard operational datasets.

In both the model (adjusted for low liquid water content) and the observations, the arrival of the cloud front at a given point lags the arrival of the elevated leading edge of southerly flow by up to several hours. In the observations, the strongest southerly wind is $8 \mathrm{~m} \mathrm{~s}^{-1}$ and the southerlies propagate to the north with a phase speed of $11.9 \pm 0.3 \mathrm{~m} \mathrm{~s}^{-1}$ (Ralph et al. 1998), although propagation is substantially impeded by interaction with the sea breeze in the vicinity of Monterey Bay. In both the observations and the model simulation, the rate of propagation drops to less than $2 \mathrm{~m} \mathrm{~s}^{-1}$ after 1800 UTC 10 June. Figures 10c and $10 \mathrm{f}$ for 0300 UTC 11 June depict this period of slow propagation. The observations and the model show a southerly low-level jet (LLJ) near Monterey Bay at 2200 UTC 10 June. In this Southern case, southerly flow does not extend north of Pt. Reyes, in contrast to the 21-22 July 1996 northern case discussed next.

\section{b. The 21-22 July 1996 event}

Figures 13a-d show subjective sea level pressure analyses from Sopko (1998) that show the develop-

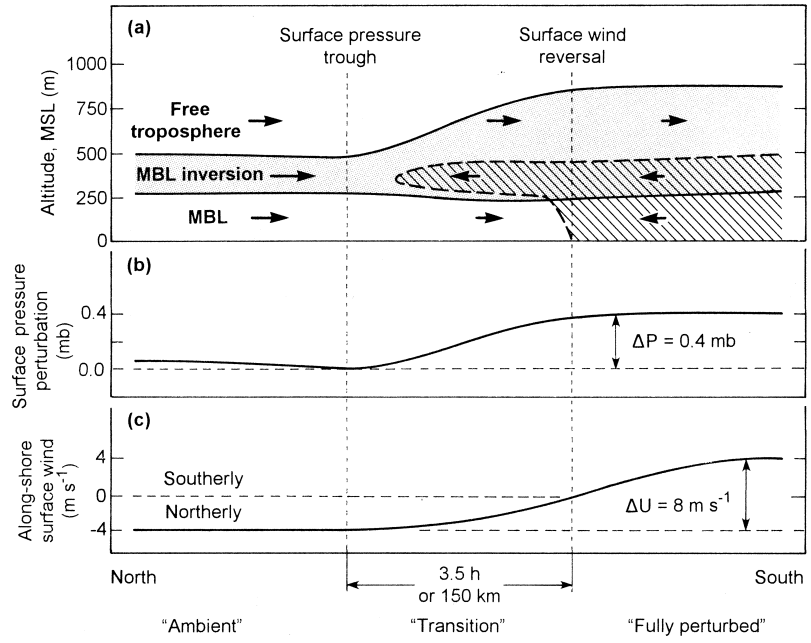

FIG. 12. (a) Idealized vertical structure of CTWR showing the inversion, marine boundary layer (MBL), and free tropospheric layers with their associated winds; (b) sea-level pressure perturbation (mb); and (c) along-shore wind component for the ambient, transition and perturbed part of a CTWR. From Ralph et al. (2000).

ment of a mesoscale offshore low near San Francisco and a coastal pressure ridge similar to that seen in the June 1994 event. The mesoscale low develops where the inland pressure trough seems to extend offshore in Fig. 13. By 1800 UTC the mesoscale low is evident in Fig. 13b and the coastal ridge is seen to slowly propagate north along the coast during the next $12 \mathrm{~h}$ (Figs. 13c and 13d). Figures 14a-c show satellite images valid at 1800 UTC 21 July and 0000 UTC and 1900 UTC 22 July, while Figs. 14d-f show model forecast streamlines at $1000 \mathrm{mb}$ and cloud liquid water at corresponding times. The propagation of cloud features is not as clearly evident in this case as the June 1994 case, although the tip of the clouds just south of Pt. Reyes in Fig. 14a do follow the southerlies that are developing there and correspond to the coastal pressure ridge in Fig. 13b. The model cloud field is somewhat more extensive than that shown in the satellite images for 1800 UTC on both 21 and 22 July (close agreement exists between the model and imagery at 0000 UTC 22 July). The inability of the model to capture every detail of the complex cloud distribution in this case highlights the challenge in predicting marine stratus even under the highly forced situation of a CTWR.

The model results show that, in this case, southerly flow begins at 1500 UTC 21 July in the vicinity of San Luis Obispo Bay, about $100 \mathrm{~km}$ south of Monterey. The leading edge of southerlies propagates to the north along the coast; however the flow shifts 
1200 UTC - 21 JULY 196

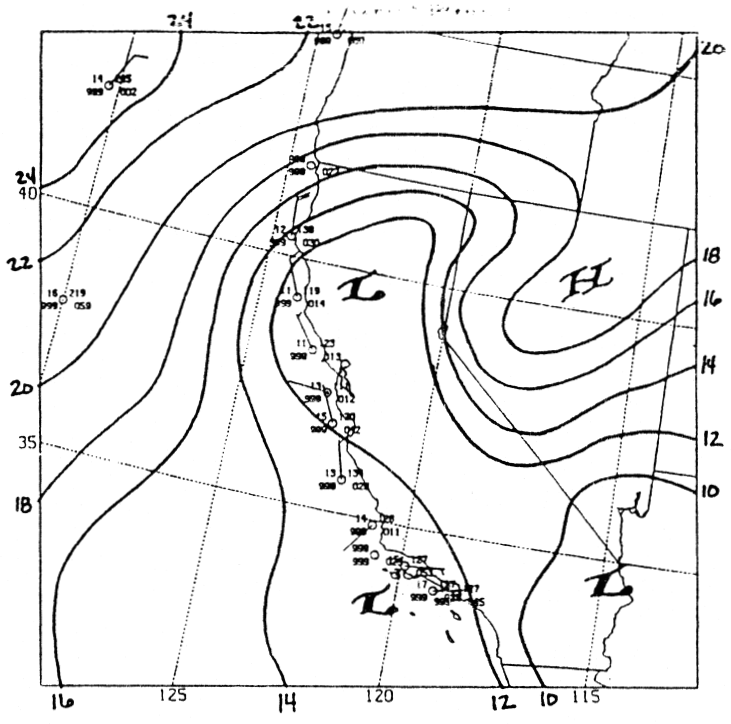

1800 UTC - 21 JULY 1996

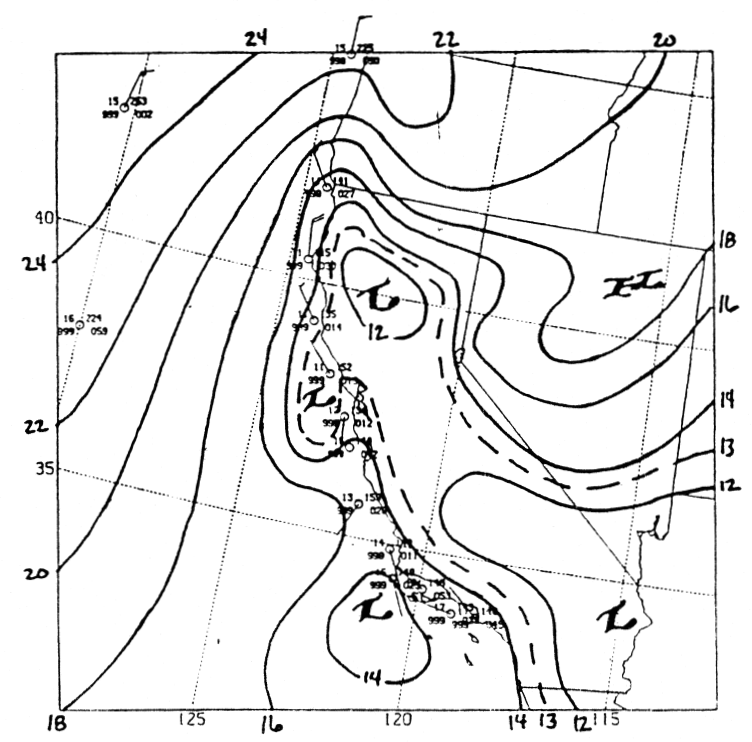

0000 UTC - 22 JULY 1996

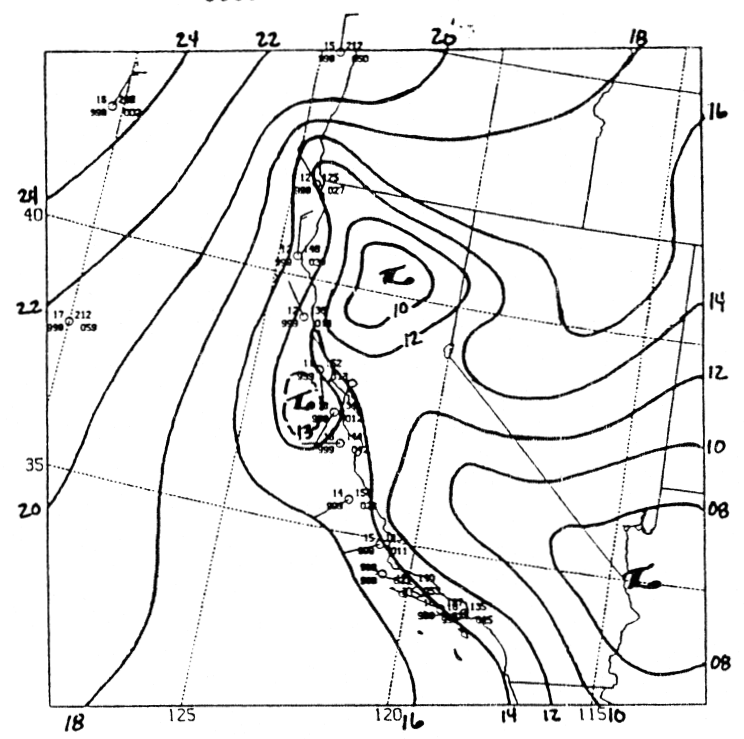

0600 UTC - 22 JULY 1996

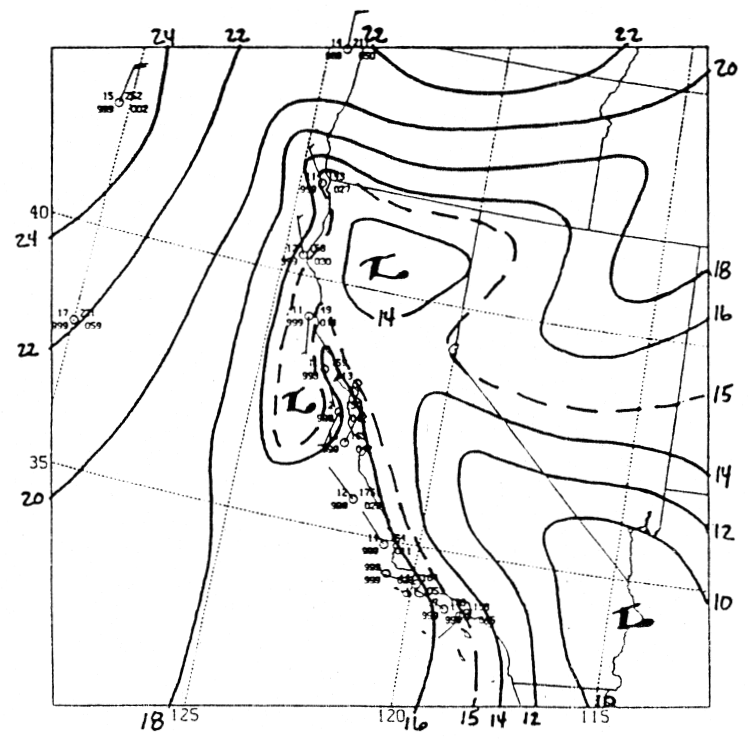

FIG. 13. Sea level pressure analyses at (upper left) 1200 UTC 21 Jul 1996, (lower left) 1800 UTC 21 Jul 1996, (upper right) 0000 UTC 22 Jul 1996, and (lower right) 0600 UTC 22 Jul 1996. The analyses were subjectively prepared using all available routine surface data plus special ECTD surface data and low-level aircraft data. Contours are every 2 mb with select 1-mb intervals added as dashed contours. From Sopko (1998).

back to northerly farther behind (south) of this leading edge. At 1800 UTC, southerly flow propagates north to Pt. Piedras Blancas and simultaneously begins near Pt. Reyes as a small closed cyclonic circulation develops there (see Figs. 13b and 14d), much as was analyzed in the 10-11 June 1994 southern case (Fig. 1). By 0000 UTC, the southern area of southerly flow propagates to Monterey Bay and unites with the northern area of southerlies. Both the model and analyses show a mesoscale low pressure center (about $1 \mathrm{mb}$ below the background pressure) is present at this time about $100 \mathrm{~km}$ offshore of Pt. Reyes (a little more north in the model than the observations), giving rise to a broad band of strong $\left(8 \mathrm{~m} \mathrm{~s}^{-1}\right)$ southerly flow near the coast (see Figs. 13c and 14e). Analysis of the momentum budget from the model indicates that the wind field in the vicinity of Pt. Reyes is nearly in geostrophic balance at this point, just six hours after the initiation of southerly flow in this location. Thus, it appears that the wind and mass fields adjust more rapidly in this northern case than they did in the southern case discussed above. Over the next $18 \mathrm{~h}$, southerly 

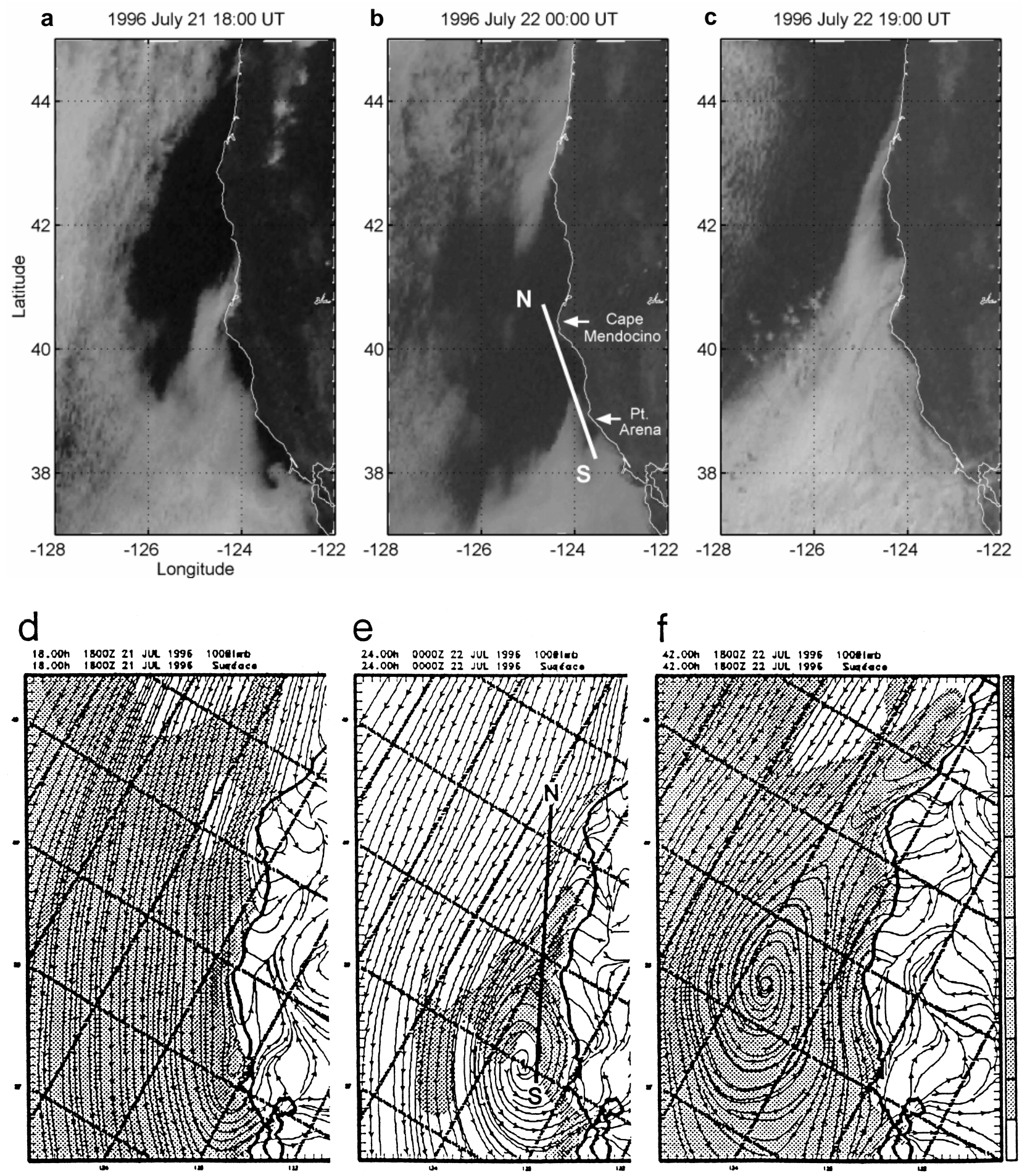

FIG. 14. GOES-9 visible satellite images valid at (a) 1800 UTC 21 Jul 1996, (b) 0000 UTC 22 Jul, and (c) 1900 UTC 22 Jul and COAMPS forecast 1000-mb streamlines and cloud liquid water (g/kg) (shaded) valid (d) $1800 \mathrm{UTC} 21 \mathrm{Jul}$, (e) $0000 \mathrm{UTC} 22 \mathrm{Jul}$, and (f) 1800 UTC 22 Jul. Cross-section planes are indicated in (b) and (e). From Thompson and Bane (1998).

flow continues to propagate to the north. Note that southerly flow north of Pt. Arena in Fig. $14 \mathrm{f}$ is not geostrophically balanced. Propagation of the southerly flow appears to "stall" on the south side of Cape
Mendocino near 1200 UTC 22 July. At 1800 UTC, the southerlies accelerate north of Cape Mendocino in a narrow zone (30 km wide) near the coast. Southerly flow is not observed north of Cape Blanco. 




C

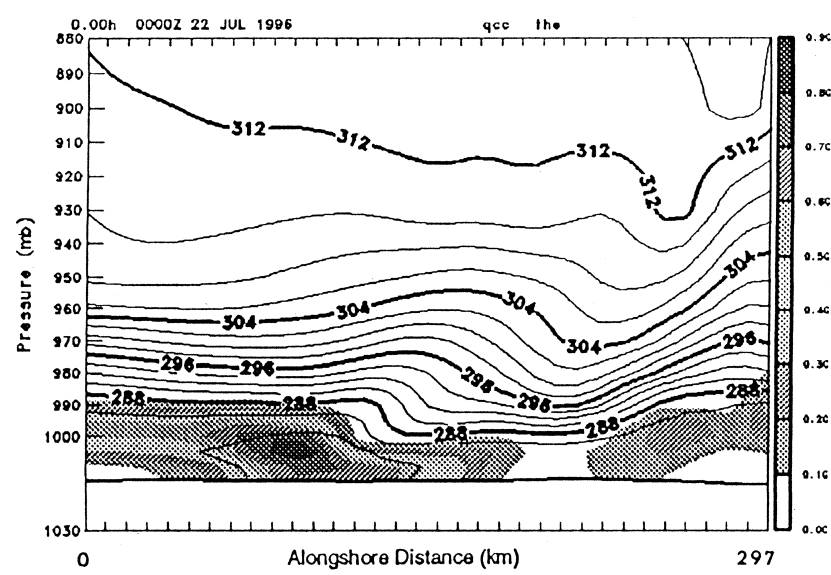



d

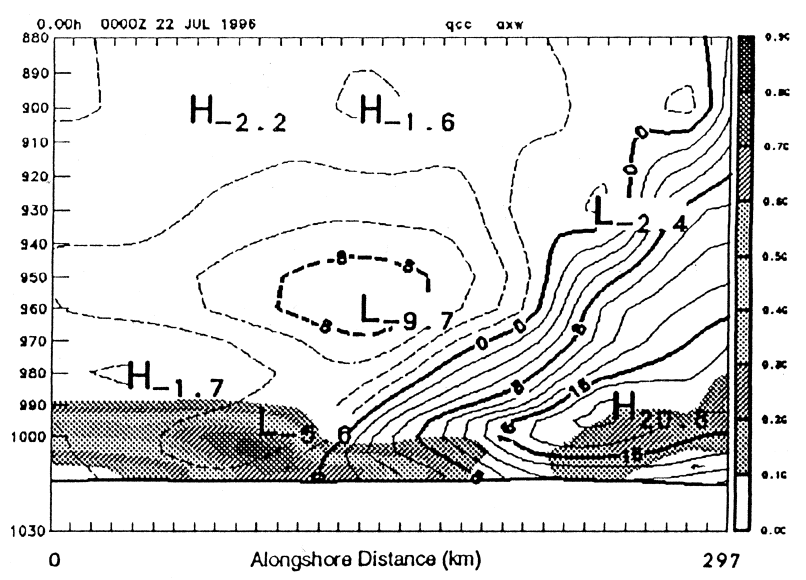

FIG. 15. Cross sections as in Fig. 11 except for 0000 UTC 22 Jul 1996. From Thompson and Bane (1998).

Shown in Figs. 15a-d are aircraft and model vertical cross sections for 0000 UTC 22 July 1996. Comparison of Figs. 15a and c shows close agreement between the aircraft observations and the model for both potential temperature and cloud water, although there are low liquid water content clouds to the north in the model. Both the model and the aircraft show a relatively constant marine layer thickness along most of the section, although the model shows a "shelf" in the cloud tops exists between about the 50- and $100-\mathrm{km}$ marks on the distance axes, which is only marginally hinted at in the observations. This steplike structure is suggestive of a gravity current with the southerly flow progressing to the north along with the slightly thicker marine layer. This is further substantiated by noting that the southerly wind speed near the surface is $5.6 \mathrm{~m} \mathrm{~s}^{-1}$, and examination of this section at later times indicates that the wind shift/thickness gradient feature progresses to the north at about $5 \mathrm{~m} \mathrm{~s}^{-1}$.
The elevated southerly maximum is somewhat greater in the model than the observations $\left(9.7 \mathrm{vs} 6 \mathrm{~m} \mathrm{~s}^{-1}\right)$ and is not vertically stacked, which again highlights the challenges in modeling the details of a CTWR even when the general evolution is captured. As shown in Fig. 15d, the separation between southerly and northerly flow (i.e., the zero isotach) is coincident with a clear change in marine layer thickness.

\section{c. Summary and comparisons of these two cases}

Perhaps the most significant of the findings about the structure of the 10-11 June 1994 CTWR came from the aircraft observations, which showed that the disturbance was contained primarily within the inversion layer, and that the leading edge of the southerlies occurs in the inversion 100-150 km ahead of the surface wind reversal and cloud leading edge (Fig. 12). These in situ measurements also revealed the rather uniform thickness of the mixed layer across the dis- 
turbance both in the along-coast (Figs. 11a and 11b) and cross-coast (not shown) directions. This structure differed substantially from the fixed point, time series perspective from the NPS profiler (Fig. 9), which suggested a dramatic thickening of the mixed layer at the disturbance's leading edge. At the overwater location of the aircraft section, there was little mixed layer thickening, indicating the lack of a gravity current-like structure within the main body of the CTWR. Although the data and the model clearly show that the MBL does not necessarily deepen in association with the surface alongshore wind reversal, which is inconsistent with the traditional two-layer theories of Kelvin waves, Ralph et al. (2000) showed that the observed structure is consistent with a mixed Kelvin waveinternal bore within a three-layer system. The three layers being the mixed layer (i.e., the MBL), the inversion capping this mixed layer, and the free troposphere above (Fig. 12). Although their results were based on a detailed analysis of the 10-11 June 1994 event, the weak $(0.4 \mathrm{mb})$ pressure rise preceding the surface wind reversal was also present in the CTWR composites created by Bond et al. (1996), which lead Ralph et al. (2000) to conclude that this structure is characteristic of most CTWRs in the region.

Preliminary analyses of the 1996 events show some similarities to the 10-11 June 1994 event, but they also clearly indicate that different events can have several different structures. Comparison of Figs. 11a,c with Figs. 15a,c suggests that the line between the layer of weaker stratification above the marine layer inversion and the inversion that sloped down to the north on 10-11 June 1994 is more flat in the 22 July case. Thus, the propagation in the middle layer (inversion) described above for the June 1994 case may not be applicable to the July 1996 case. As this propagation within the inversion appeared to play an important role in the dynamics as well as the initiation of the June 1994 CTWR, its absence in the July 1996 case may have profound dynamical implications (Thompson and Bane 1998). The July 1996 CTWR seems more consistent with a two-layer interpretation than does the June 1994 CTWR, given the deepening of the MBL behind the leading edge of the disturbance. Even so, Fig. 15b shows that the leading edge of the southerly winds in the July 1996 case exists above the surface in the stratified inversion, as was the case for the June 1994 case; however, the July 1996 CTWR exhibits a thicker layer of southerlies than does the June 1994 event, extending upward from the inversion to at least $850 \mathrm{mb}$. These differences in me- soscale structure are interesting and point to the complexity of these disturbances. More extensive analysis of these and the other cases from 1996 are presently under way.

\section{Model studies}

A variety of numerical modeling studies were conducted as part of the ECTD and can be grouped into two classes of investigation. First, a number of studies have focused primarily on the disturbance itself and its behavior under a variety of external forcings. These studies have employed both reduced gravity models as well as full physics primitive equation models using idealized conditions. The other class of model studies comprises those that attempt to simulate the complete evolution of the atmosphere including the larger-scale background and the disturbance, such as the COAMPS simulations described in the previous section. These studies have used primitive equation models, full-physics as well as simplified, to simulate either actual events or idealized atmospheric structures that contain the salient characteristic features of the real atmosphere during a CTWR. These two classes of model studies are described in the two subsections that follow.

\section{a. Simulations of CTWR characteristics}

Idealized model simulations have been conducted to provide insight into the basic dynamical properties of CTWRs as well as their relationship to synopticscale forcing. The simplest idealized model of coastal trapping utilizes a reduced-gravity, shallow-water model, consisting of a single active layer of homogeneous fluid beneath a passive, thick, homogeneous upper layer of slightly smaller density, where the coastal orography is represented by a vertical wall. The investigation of coastally trapped disturbances in the lower atmosphere using shallow-water models was begun by Gill (1977), who was motivated by observations along the coast of South Africa. It has been continued and extended by Nguyen and Gill (1981), Bannon (1981), Hermann et al. (1990), Reason and Steyn (1990, 1992), Rogerson and Samelson (1995), Klemp et al. (1995), and more recently by Samelson and Rogerson (1996) to examine the CTWR evolution when forced by the MB96 synoptic climatology.

The MB96 climatological synoptic evolution may be represented in an idealized manner by the westward propagation of a low pressure center (lee trough) 
across the coastal boundary. When the linear, reducedgravity, shallow-water model is forced by this pressure field, the response is qualitatively and, to some degree, quantitatively consistent with many aspects of observed CTWRs (Samelson and Rogerson 1996). The response occurs in two stages, and the dynamics of the response to the cross-shore and alongshore pressure gradients are distinct. As the region of low pressure moves offshore, the cross-shore pressure gradient forces ageostrophic offshore flow near the coastal wall, and farther offshore is balanced by an alongshore geostrophic flow. The resulting divergence of the crossshore flow thins the stable layer by several hundred meters near the coast, but there is no alongshore wind response at the coast and no alongshore propagation of the disturbance. In contrast, the imposed alongshore pressure gradient forces a reversal of the alongshore winds at the coast to the south of the low. The alongshore wind and the stable layer thickness responses at the coast are together described by forced Kelvin wave dynamics. Far from the coast, the cross-shore flow response to the alongshore pressure gradients is geostrophic, and the convergence to the south and divergence to the north in this geostrophic cross-shore flow force the coastal Kelvin wave. Similar to a free Kelvin wave, the alongshore flow at the coast in this forced Kelvin wave is both in geostrophic balance with and directly accelerated by the alongshore pressure gradient.

The combination of these two effects leads to a coastally trapped response that occurs in two stages. During the generation phase, the stable layer lifts and falls along the coast in response to convergence and divergence of both ageostrophic and geostrophic cross-shore flow, and the alongshore winds are accelerated by the alongshore pressure gradient forcing. During the propagation and decay phase, the pressure forcing weakens, and the stable layer thickness along the coast is controlled primarily by the convergence and divergence of the alongshore flow, while the alongshore winds are driven primarily by alongshore pressure gradients caused by these changes in thickness. The forced response resembles a free Kelvin wave more closely during the second stage, which occurs after the low has been pushed offshore. The evolution of the coastal pressure, thickness, and alongshore velocity in the linear model are shown in Fig. 16, which shows a change from locally forced to propagating near $t=1$ day. For this simple model, the forced Kelvin wave propagates rather uniformly unlike many observed cases where the propagation can vary over time.

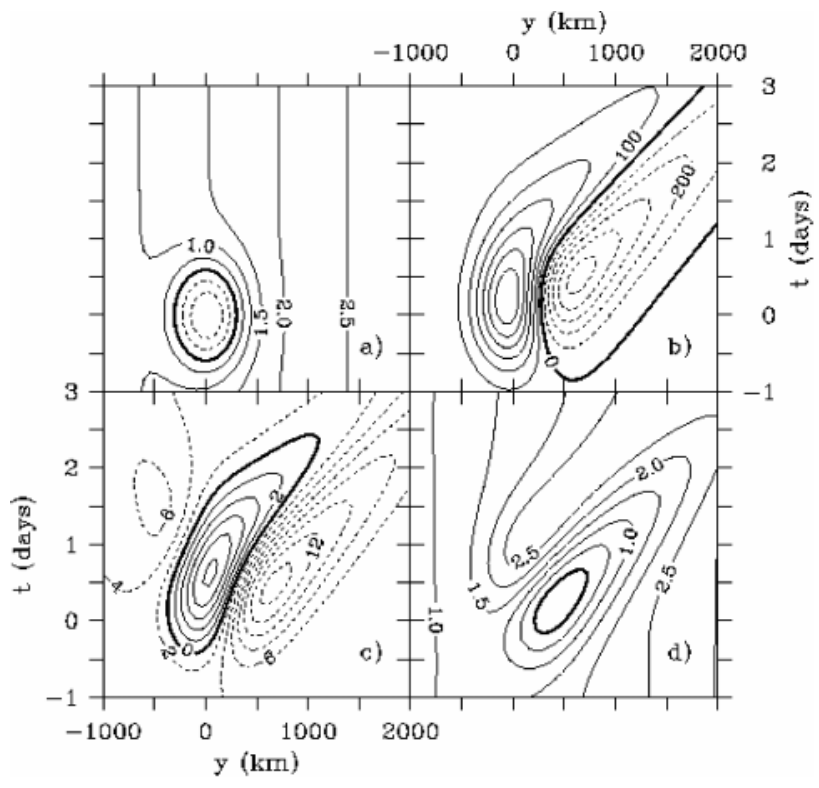

FIG. 16. (a) Coastal pressure forcing and (b)-(d) model response as a function of alongshore distance and time for an idealized, linear, CTWR model. (a) Imposed pressure forcing, $p_{a}$, contoured in increments of $0.5 \mathrm{mb}$. (b) Marine layer thickness, $\zeta$, contoured in increments of $100 \mathrm{~m}$. (c) Alongshore velocity, $v+V_{0}$, contoured in increments of $2 \mathrm{~m} \mathrm{~s}^{-1}$. (d) Surface pressure, $p$, contoured in increments of $0.5 \mathrm{mb}$. From Samelson and Rogerson (1996).

A halting of the northward propagation of CTWRs at capes and headlands is sometimes seen observationally and work by Skamarock et al. (1996) shows that Kelvin waves, rotationally trapped bores and gravity currents propagate around bends without any loss in amplitude in the absence of northerly winds at the bend. This suggests that factors other than coastline shape contribute to nonuniform propagation and the formation of eddies near headlands and capes. Rogerson (1999) has recently demonstrated that nonlinear coastally trapped disturbances in the shallowwater model may be halted near coastline bends by hydraulically supercritical northerly ambient flow (Dorman 1985; Winant et al. 1988; Samelson 1992), and has described an associated generation of eddies that bear a striking resemblance to features in satellite images of stratus during a coastally trapped event off California in May 1982.

Other recent theoretical work has begun to address aspects of the vertical structure of observed CTWRs. Based on the analysis of linear models with continuous and two-layer stratification, Samelson (1999) has suggested that the observed vertical structure of isotherms at the leading edge of the 10-11 June 1994 event may arise during the transition from a directly 
forced, barotropic, alongshore velocity response to a regime dominated by wave propagation, as coastally trapped vertical modes excited by mesoscale pressure gradients begin to disperse at differing phase speeds.

The Colorado State University Regional Atmospheric Modeling System (RAMS) has also been used to make a number of idealized two- and threedimensional CTWR simulations to extend the results of the reduced gravity models. RAMS is a versatile mesoscale model allowing tailored applications to a wide range of atmospheric phenomena and is described in detail in Pielke et al. (1992). Idealized gravity current-like CTWRs are initialized in RAMS by cooling the southern part of the model domain, in a shallow layer near the coast (Jackson and Reason 1995). This results in an increase in density and pressure in that zone, and the propagation northward along the coastal mountains, of a southerly wind reversal (Fig. 17). A number of numerical experiments have been made to test the sensitivity of this type of CTWR to topographic configuration, background synoptic conditions, size and intensity of the initiating cold pool, etc. Initial results (Fu et al. 1997) suggest that these gravity current-like CTWRs are sensitive to the size and intensity of the initiating cold pool. Large cold pools with large amounts of cooling of a scale which allows geostrophic adjustment to take place result in CTWRs that decay more rapidly than those initiated with smaller cooling areas. If the cooling amount or area is too small however, the supply of cold air becomes the limiting factor and the CTWR will also decay more rapidly. Sea surface temperature values similar to those of the cold pool seem to enhance propagation speed and are associated with idealized CTWRs, which exhibit sharp surface transitions. When coastal mountains are less steep they are less effective in blocking onshore flow, and CTWR intensity is reduced. Simulated CTWRs attenuate and reduce their cross-shore scale when they propagate past gaps in the coastal mountains.

\section{b. Simulations of complete atmospheric evolution}

The shallow-water model approach is limited in that it treats the synoptic forcing as an imposed external forcing and allows no feedback on the atmospheric structure above the marine layer. To provide a clearer link between the synoptic-scale forcing and the complete three-dimensional evolution of the atmosphere, Skamarock et al. (1999) utilized a three-dimensional, nonhydrostatic, primitive equation model and idealized climatological conditions to investigate the

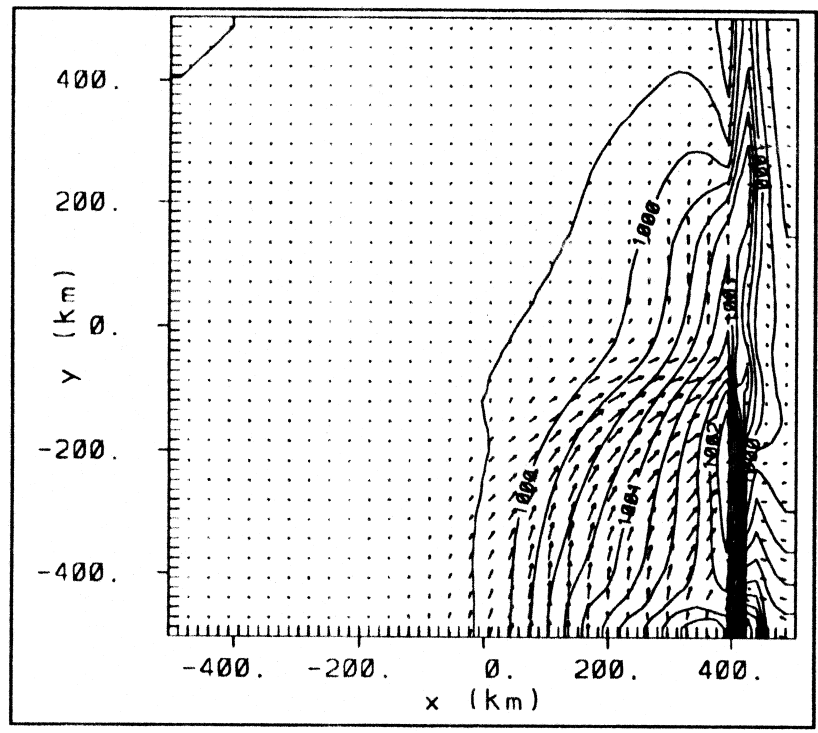

FIG. 17. CTWR from RAMS model simulation of Jackson and Reason (1995). Contours are in hPa with a $0.25 \mathrm{hPa}$ interval.

coastal evolution due to an imposed offshore forcing similar to that described by MB96. The time and space scales of the synopticforcing were based largely on those documented in the 10-11 June 1994 event. Ralph et al. (1998) found offshore flow occurred over most of California with a $5 \mathrm{~m} \mathrm{~s}^{-1}$ maximum centered near the Monterey Bay region. This offshore flow persisted for about 3 days, similar to the imposed forcing used by Skamarock et al. (1999). Their results are shown in Fig. 18 for their reference simulation, which resembles remarkably well the observed structure of the 10 June 1994 CTWR as well as other previously observed events. The idealized model simulations show the development of a mesoscale coastal low due to evacuation of the marine layer and lee troughing in response to the offshore flow across the coastal mountains after about 1 day. Figures 1 and 13 show a similar evolution of sea level pressure with the development of a weak offshore mesoscale low. As the low-level flow comes into geostrophic balance with this mesoscale coastal low, the westerly flow to the south encounters the coastal mountains and raises the marine layer, which accelerates the flow to the north as a coastally trapped disturbance. Coastal southerlies consequently propagate north into the region where the marine layer has been pushed offshore and the coastal low elongates and is displaced further offshore on day 2 . This character of the evolution differs from that of the shallowwater simulations in that the shallow water layer initially rises into the low, whereas these three dimensional simulations show the MBL being depressed and 


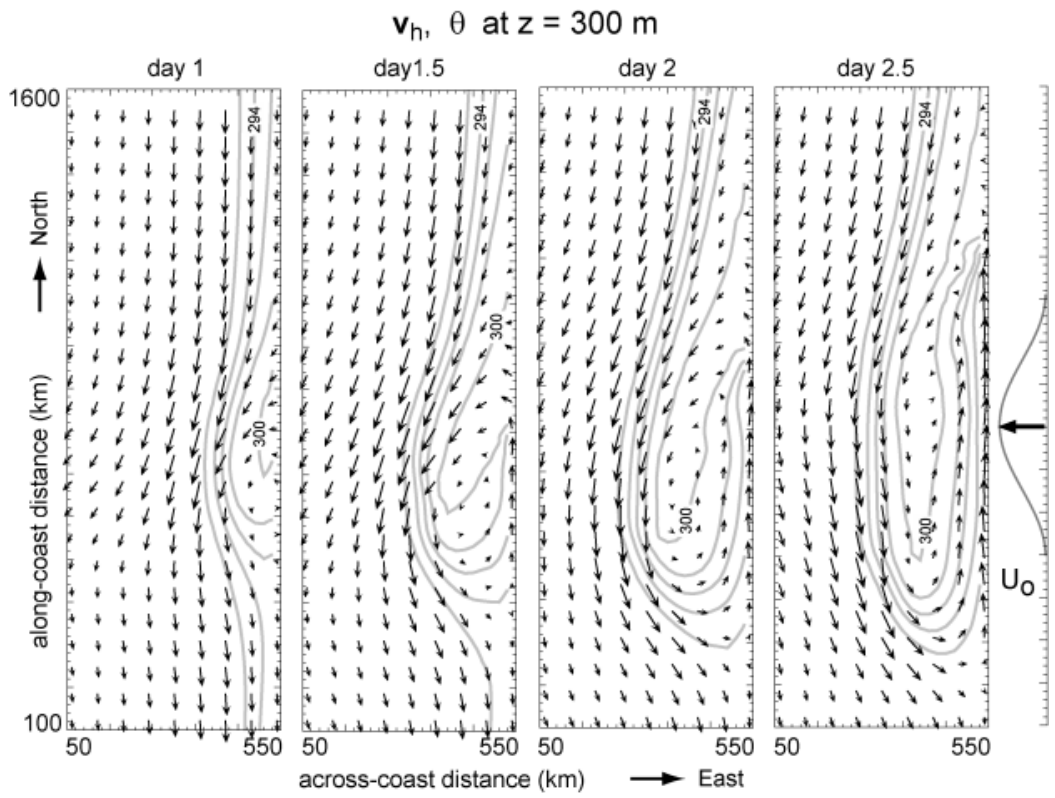

FIG. 18. Evolution of the potential temperature (K) (contours) and surface winds for the idealized primitive equation model simulations of Skamarock et al. (1999). Maximum vector in the plots is $14 \mathrm{~m} / \mathrm{s}$. the evolution of the event. The synoptic situation under which this gravity current-like event occurred involved the northwestward tracking of a midlevel low across northern California/southern Oregon and out over the Pacific. Associated with this low were offshore warm winds ahead of the CTWR, and a cool onshore flow in the Southern California Bight (Fig. 19). These flows then reversed the usual southward-directed pressure gradient force along the West Coast, and promoted convergence of relatively cool, dense air against the coastal mountains to the south. Deceleration of this onshore flow by the coastal mountains (Pierrehumbert and Wyman 1985; Reason 1994), together with the favorable background synoptic environment, then lead to the propagation of a gravity current-like CTWR north-

moved offshore similar to the evolution documented by observations. The CTWRs inthese simulations are freely propagating disturbances once they are initiated by the local deepening of the marine layer. Skamarock et al. also find evidence of topographically trapped Rossby waves above the MBL in their simulations, and these waves may be responsible for the northward propagation of the lee trough documented in MB96.

Simulations of numerous observed cases of CTWRs has also been done using a variety of modeling systems. These simulations provide insight into our ability to routinely predict these events from routine observations. COAMPS was run in real time in support of aircraft operations during June and July 1996 and has been used in research studies of CTWRs (Thompson et al. 1997; Thompson and Bane 1998). Comparisons of COAMPS results with observations for the 10-11 June 1994 and 21-22 July 1996 CTWRs were presented above in section 5 . In addition to these COAMPS studies, RAMS has been used to make realistic simulations (Guan et al. 1998; Jackson et al. 1999) of the strong CTWR event of 15-18 May 1985 , documented by Mass and Albright (1987). These studies have suggested that RAMS can also be successfully applied to simulate, and further the understanding of, CTWR events where the synoptic forcing is strong and local boundary layer dynamics are less important for

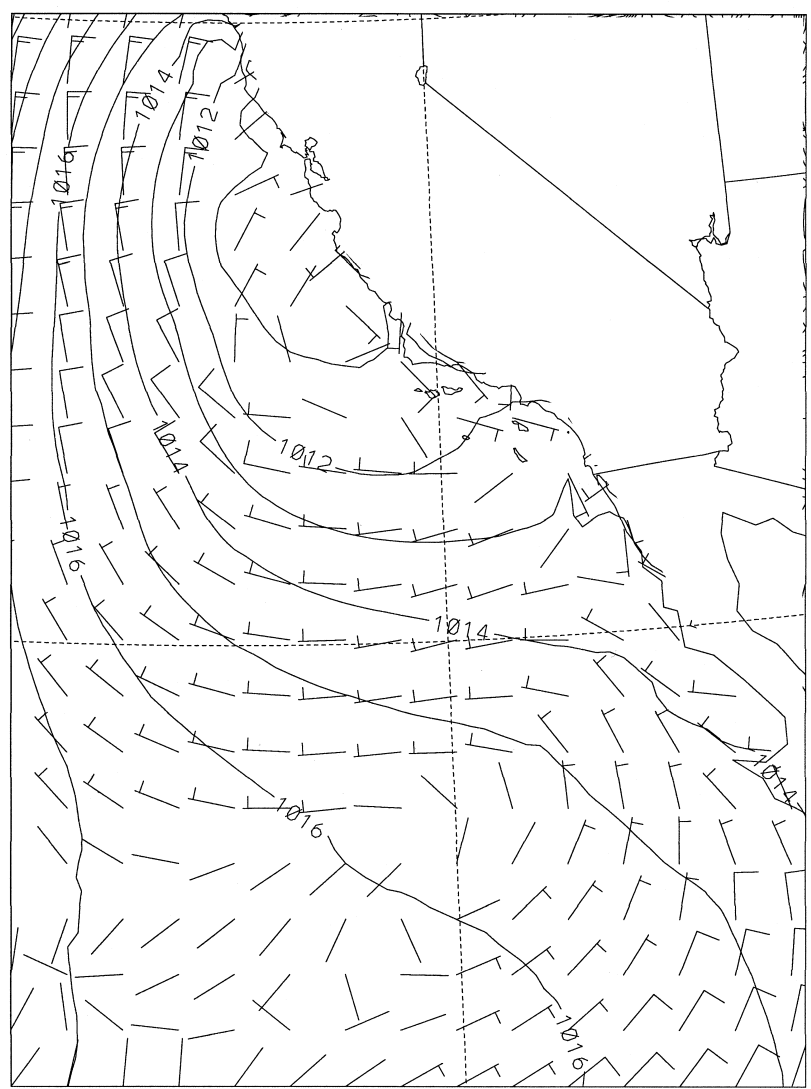

FIG. 19. Low-level circulation from a RAMS model simulation of the 15-18 May 1985 CTWR (Jackson et al. 1999). Pressure given in $\mathrm{mb}$. 
wards as far as the northern tip of Vancouver Island. Force balance diagnostics from the RAMS simulation (Fig. 19, Jackson et al. 1999) reinforce the importance of the decelerating onshore flow to the south for initiating this event. The southerly (positive) meridional wind tendency in the California Bight seen in Fig. 20 is due in part to a weakening of the northerly (negative) Coriolis tendency. The decreased northerly Coriolis tendency is caused by deceleration and divergence of the onshore flow in the offshore area, and allows the southerly (positive) pressure gradient tendency to dominate, thus initiating the CTWR.

Similar to a previously documented gravity current-like CTWR that reached northern Vancouver Island (Reason and Dunkley 1993), this event terminated essentially because favorable synoptic conditions no longer existed. However, unlike the Reason and Dunkley CTWR, there was little evidence of significant weakening or stalling of the event near large gaps in the coastal mountains between northern Oregon and Vancouver Island. These differences in propagation characteristics emphasize the difficulties faced in forecasting CTWRs.

\section{Progress in understanding}

After five years of rather intensive study, considerable progress in understanding the character and initiation of CTWRs has been made. The fundamental issue has been and is still the relative roles of MBL depth changes versus external forcing above the MBL. The observational and modeling studies have complemented each other very well to further our understanding of the basic dynamics of these coastal weather events and indicate the relationship between the MBL and external forcing in the few events studied. The initiation mechanisms are much better understood from both modeling and observational perspectives. The synoptic-scale structure defined by MB96 has been shown by Skamarock et al. (1999) and Samelson and Rogerson (1996) to be capable of spawning a coastally trapped Kelvin wave in which the MBL depth differences that drive the disturbance are externally forced, at least initially. Analysis of the well documented CTWR of 10-11 June 1994 by Ralph et al. (1998) indicated that offshore advection of warm continental air across a 600-1000-km long portion of the coast was the primary mechanism for producing the region of coastal pressure falls and the ensuing low pressure trough prior to CTWR development in that case. Although topographic lee troughing due to downslope flow over the coastal ranges did not dominate the observed evolution in that case, it is possible that both mechanisms could be important in other cases. The importance of offshore advection of warm continental air may account for the lack of CTWRs along the California coast during the cool season when offshore flow is more prevalent in this region. The study by Nuss (1998) supports the model of Skamarock et al. (1999) in that propagating disturbances seem to arise only during periods of synoptic-scale offshore flow that forces a coastal lee trough. Other synoptic patterns that result in reversing the pressure gradient do not lead to propagating CTWRs. These studies provide a clear relationship between the synoptic-scale forcing and the coastal mesoscale response. Preliminary analyses of the 1996 events suggest that there is considerable variability in both the synoptic-scale forcing and the coastal response for CTWRs. The forcing can be very short-lived and still produce a short-lived CTWR such as the 5 June 1996 case. The large-scale conditions required to create a CTWR involve a significant weakening, and eventual reversal, of the alongshore pressure gradient from its normal southward decrease of surface pressure. While Skamarock et al. (1999) and Ralph et al. (2000) show this can occur south of an axis of maximum offshore flow and its associated warm advection and/or downslope warming, the climatological northerly flow that usually inhibits CTWR formation or propagation is also accelerated to the north of this axis. Thus, the very conditions that can lead to a CTWR, also create a limit to its northward extent, barring the anomalous northward movement of this favorable synoptic-scale forcing.

Significant insight into the structure and governing dynamics of these events has come through detailed observational and modeling studies. The analysis of Ralph et al. (1998, 2000) raises concern about the applicability of two-layer shallow-water theory to the phenomenon because these studies clearly showed that these disturbances can occur without the anticipated change in the MBL depth, and instead can sometimes be described as an upward expansion of the inversion capping the MBL. Ralph et al. (2000) showed that this event was most consistent with a mixed wave-bore propagating on the MBL inversion, while the MBL acted as a quasi-rigid lower boundary. This showed the strong contribution of MBL structure to the disturbance's evolution although the initiation was externally forced. Although com- 



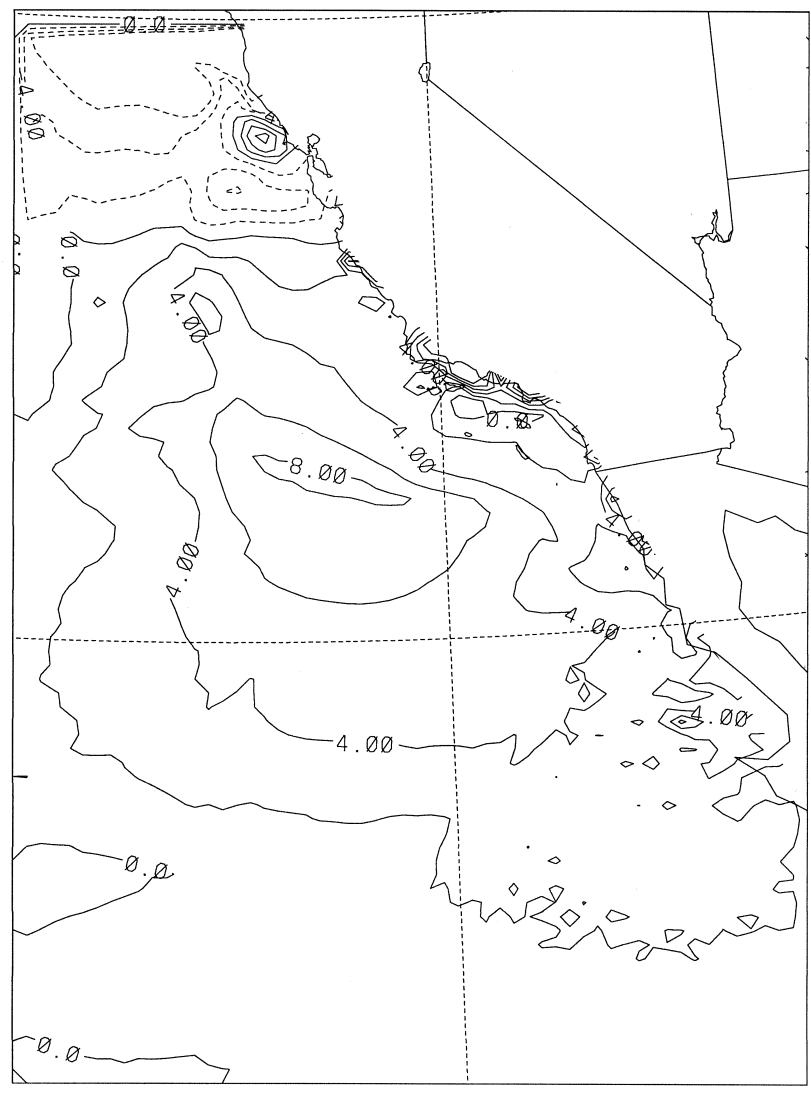

FIG. 20. Time tendency of the meridional wind component at 1600 UTC 15 May 1985 at a level 118 m above sea-level: (a) total tendency; (b) tendency due to the pressure gradient force; and (c) tendency due to the coriolis force. The tendency is in $10(-4) \mathrm{m} \mathrm{s}(-2)$ and contoured every $2 \times 10(-4) \mathrm{m} \mathrm{s}(-2)$. From Jackson et al. (1999).

740

Vol. 81, No. 4, April 2000 
parison of the 10-11 June 1994 event to the composite of many events (Bond et al. 1996) by Ralph et al. (2000) suggests that this structure may be characteristic of many CTWRs, preliminary analysis of the 1996 events suggests that case to case differences in the MBL and inversion structure occur. In fact the July 1996 event had little MBL structure to account for the pressure gradient driving this disturbance. This indicates that the structure and governing dynamics of CTWRs can vary significantly from one event to another. Model simulations (Jackson et al. 1999; Thompson et al. 1997) using observational data have also revealed this variability by showing that CTWRs can be marked by a substantial change in MBL depth and thus may be better characterized by internal bore or gravity current behavior. Thus, the cases observed and modeled during the ECTD have not shown that all CTWRs can be described as either internal bores, Kelvin waves, gravity currents, or simply ageostrophic downgradient flow. Instead it appears that all these processes can play a role, but with differing degrees in different events. The idealized studies of the disturbance itself show that the distinction between Kelvin wave, internal bore, or gravity current characterizations for CTWRs it not critical in that they all propagate and both observations and theoretical studies show that Kelvin waves can evolve into bores and gravity currents.

The differences in forcing that occur from one case to another may help to determine which dynamic mechanisms are most important, and in a longduration event, how a CTWR may evolve from one type to another. Clear differences in forcing likely exist between events best described as Kelvin waves or bores and those described as gravity currents or ageostrophic downgradient flow that does not depend on MBL depth. The ECTD has established that several environmental factors could help distinguish which type of event will occur: the duration and alongshore extent of the offshore flow apparently influences the propagation characteristics (Nuss 1998), static stability above the MBL influences the upward gravity wave energy propagation that influences the rate of steepening of nonlinear disturbances (Skamarock et al. 1999), and the strength of lee troughing versus offshore warm advection could determine if the MBL is simply made more shallow or eliminated altogether which determines the basic dynamic mechanism as suggested by Klemp et al. (1997).

Another key result from the ECTD has been the ability of full physics models using real atmospheric data to demonstrate skill at simulating CTWRs. Both the RAMS (Jackson et al. 1999) and COAMPS (Thompson et al. 1997; Thompson and Bane 1998) have produced representative simulations of five different CTWR events. This indicates that the models are potentially capable of forecasting CTWRs given sufficiently accurate initial conditions. Given the possible sensitivity of the dynamic mechanisms to various factors, the routine prediction of these events several days in advance is not certain. Clearly the robust synoptic signature found by MB96 and highlighted in the 10-11 June 1994 event by Ralph et al. (1998) and other cases by Sopko (1998) suggest that the numerical models can predict these events with some skill. A key remaining question is what aspects of the larger scale environment are responsible for poor predictions and what observational resources are required to improve those predictions.

\section{Future directions}

Although the ECTD has provided important insights into CTWRs, the limited number of cases observed has prevented resolution of all the outstanding issues. The detailed evolution of the structure of a CTWR has not been observed over its life cycle, and the causes of the decay and cessation of propagation have not been specifically addressed in these studies. Observations of CTWRs that reach the northern tip of Vancouver Island suggest that in some cases these events may significantly weaken or even stall at prominent gaps in the coastal mountains like the Columbia River mouth or the Strait of Juan de Fuca (Reason and Dunkley 1993). Since this behavior does not always happen (Jackson et al. 1999), problems are posed for forecasting. To study the potential influence of the significant variations in the coastal topography of the Pacific Northwest and Vancouver Island coasts, a joint field program utilizing in situ, remote, and aircraft observations is being planned by researchers at the Universities of Northern British Columbia, Melbourne, and British Columbia. Numerical simulations of the ECTD cases and the analysis of the observational data continue and will likely shed further light on these subjects. Additional cases are needed to more fully determine the links between the forcing and the mesoscale coastal response that is hinted at in these four cases and the synoptic studies. In addition, the role of uncertainties and errors in the physical parameterizations, such as turbulence, radiation, 
or cloud microphysics, in producing accurate model forecasts is unknown and would benefit from additional detailed case studies.

Routine quasi-operational mesoscale modeling of West Coast weather is beginning to provide model predictions of CTWR events that may help to extend the studies begun under the Coastal Meteorology ARI. Certainly, as noted above, the key ingredients necessary for skillful, consistent prediction of these events is not fully defined although insights from the ECTD do point in several definite directions. The primary question concerns the sensitivity of actual CTWR events to the range of errors in the routine observation of the West Coast atmosphere. Detailed studies of more CTWR events may help define the necessary observations to characterize the large-scale forcing and background environment that shape the evolution of a CTWR. The continued analysis of the other events observed during 1996 will help, but may not address the full range of variability in the forcing of CTWRs.

Finally, the research undertaken during the ECTD has relied heavily on available routine coastal observations and enhancements to them for research purposes. Degradation of the coastal observing system is likely to severely hamper further progress on this subject. The continued operation of coastal profilers by NOAA ETL, NPS, and others is highly beneficial to this type of research. Operational forecasters may require these profiler and other coastal observations to properly sort out the evolution of CTWRs based on the results of this work. A key future direction must be to define the needed observing systems to properly model and forecast these types of coastal disturbances on a routine basis.

Acknowledgments. Most of the authors were supported through the Office of Naval Research Coastal Meteorology Accelerated Research Initiative, one of the authors (WTT) was supported by Program Element 0601153N, Naval Research Laboratory.

\section{References}

Bane, J. M., 1997: Airflow and stratification in propagating southerly surges within the summertime marine layer off California and Oregon. Preprints, 12th Symp. on Boundary Layers and Turbulence, Vancouver, BC, Canada, Amer. Meteor. Soc., 346-347.

— S. M. Haines, L. Armi, and M. H. Sessions, 1995: The California coastal marine layer: Winds and thermodynamics. Tech. Rep. CMS95-1, University of North Carolina Aircraft Measurement Program, 289 pp. [Available from University of
North Carolina, Marine Sciences Department, Chapel Hill, NC 27599-3300.]

Bannon, P. R., 1981: Synoptic-scale forcing of coastal lows: Forced double Kelvin waves in the atmosphere. Quart. J. Roy. Meteor. Soc., 107, 313-327.

Bond, N., C. Mass, and J. Overland, 1996: Coastally trapped wind reversals along the U.S. West Coast during the warm season. Part I: Climatology and temporal evolution. Mon. Wea. Rev., 124, 430-445.

, and Coauthors, 1997: The Coastal Observation and Simulation with Topography (COAST) Experiment. Bull. Amer. Meteor., Soc., 78, 1941-1955.

Dorman, C. E., 1985: Evidence of Kelvin waves in California's marine layer and related eddy generation. Mon. Wea. Rev., 113, 827-839.

- 1987: Possible role of gravity currents in northern California's coastal summer wind reversals. J. Geophys. Res., 92, 1497-1506.

, 1988: Comments on "Coastal southerlies and alongshore surges of the west coast of North America: Evidence of mesoscale topographically trapped response to synoptic forcing." Mon. Wea. Rev., 116, 2401-2406.

__ 1997: Comments on "Coastally trapped wind reversals along the U.S. west coast during the warm season. Part II: Synoptic evolution.” Mon. Wea. Rev., 125, 1692-1694.

_ L. L. Armi, J. M. Bane, and D. P. Rogers, 1998: Sea surface mixed layer during the 10-11 June 1994 California coastally trapped event. Mon. Wea. Rev., 126, 600-619.

Durkee, P. A., K. J. Noone, and R. T. Bluth, 2000: The Monterey Area Ship Track Experiment. J. Atmos. Sci., in press.

Fu, H., C. J. C. Reason, and P. L. Jackson 1997: The effects of boundary and initial conditions on idealized coastal trapped disturbance evolution. Preprints, 12th Symp. on Boundary Layers and Turbulence, Vancouver, BC, Canada, Amer. Meteor. Soc., 350-351.

Gill, A. E. 1977: Coastally trapped waves in the atmosphere. Quart. J. Roy. Meteor. Soc., 103, 431-440.

Guan, S., P. L. Jackson, and C. J. C. Reason 1998: Numerical modeling of a coastal trapped disturbance. Part I: Comparison with observations. Mon. Wea. Rev., 126, 972-990.

Hermann, A. J., B. M. Hickey, C. F. Mass, and M. D. Albright 1990: Orographically trapped coastal wind events in the Pacific Northwest and their oceanic response. J. Geophys. Res., 95, 13 169-13 193.

Hodur, R., 1997: The Navy's Coupled Ocean/Atmosphere Model (COAMPS). Mon. Wea. Rev., 125, 1414-1430.

Jackson, P. L., and C. J. C. Reason, 1995: Numerical modeling of coastally trapped disturbances, Preprints, Seventh Conf. on Mountain Meteorology, Breckenridge, CO, Amer. Meteor. Soc., 189-190.

$\ldots, \ldots$, and S. Guan, 1999: Numerical modeling of a coastal trapped disturbance. Part II: Structure and dynamics. Mon. Wea. Rev., 127, 535-550.

Klemp, J., R. Rotunno, and W. Skamarock 1995: Shallow-water model simulations of coastally trapped disturbances. Preprints, Seventh Conf. on Mountain Meteorology, Breckenridge, CO, Amer. Meteor. Soc., 197-202.

,-- , and -1997 : On the propagation of internal bores. J. Fluid Mech., 331, 81-106. 
Mass, C. F., and M. D. Albright, 1987: Coastal southerlies and alongshore surges of the west coast of North America: Evidence of mesoscale topographically trapped response to synoptic forcing. Mon. Wea. Rev., 115, 1707-1738.

— and - 1988: Reply. Mon. Wea. Rev., 116, 2407-2410.

_ , and N. Bond, 1996: Coastally trapped wind reversals along the U.S. west coast during the warm season. Part II: Synoptic evolution. Mon. Wea. Rev., 124, 446-461.

— wind reversals along the U.S. west coast during the warm season. Part II: Synoptic evolution."' Mon. Wea. Rev., 125, 16951697.

—, M. D. Albright, and D. J. Brees, 1986: The onshore surge of marine air into the Pacific Northwest: A coastal region of complex terrain. Mon. Wea. Rev., 114, 2602-2627.

Neiburger, M., D. S. Johnson, and C. W. Chien, 1961: Studies of the Structure of the Atmosphere over the Eastern North PacificOcean. Vol. I, The Inversion over the Eastern North Pacific Ocean, University of California Press, 94 pp.

Nguyen, N. A., and A. E. Gill, 1981: Generation of coastal lows by synoptic-scale waves. Quart. J. Roy. Meteor. Soc., 107, 521-530.

Nuss, W. A., 1996: Coastal Meteorology Science Plan. Naval Postgraduate School Tech. Rep. NPS-MR-96-001, 33 pp. [Available from Naval Postgraduate School, 589 Dyer Rd., Monterey, CA 93943-5114.]

_- 1998: Synoptic-scale structure and the character of coastally-trapped disturbances. Preprints. Second Conf. on Coastal Atmospheric and Oceanic Prediction and Processes, Phoenix, AZ, Amer. Meteor. Soc., 186-193.

Pielke, R. A., and Coauthors, 1992: A comprehensive meteorological modeling system-RAMS. Meteor. Atmos. Phys., 49, 69-91.

Pierrehumbert, R. T., and B. Wyman, 1985: Upstream effects of mesoscale mountains. J. Atmos. Sci., 42, 977-1003.

Ralph, F. M., L. Armi, J. M. Bane, C. E. Dorman, W. D. Neff, P. J. Neiman, W. A. Nuss, and P. O. G. Persson, 1998: Observations and analysis of the 10-11 June 1994 coastally trapped disturbance. Mon. Wea. Rev., 126, 2435-2465.

—, P. J. Neiman, P. O. G. Persson, J. M. Bane, M. L. Cancillo, J. M. Wilczak, and W. A. Nuss, 2000: Kelvin waves and internal bores in the marine boundary layer inversion and their relationship to coastally trapped wind reversals. Mon. Wea. Rev., 128, 283-300.
Reason, C. J. C., 1994: Orographically trapped disturbances in the lower atmosphere: scale analysis and simple models. Meteor. Atmos. Phys., 53, 131-136.

— the South African coastal low. Quart. J. Roy. Meteor. Soc., 116, 1133-1151.

— lower atmosphere: dynamic commonalities and geographic diversity. Prog. Phys. Geogr., 14, 178-198.

$\longrightarrow$, and -1992 : The dynamics of coastally trapped mesoscale ridges in the lower atmosphere. J. Atmos. Sci., 49, 16771692.

— British Columbia. Atmos.-Ocean, 31, 235-258.

Rogers, D. P., and Coauthors, 1998: Highlights of Coastal Waves 1996. Bull. Amer. Meteor. Soc., 79, 1307-1326.

Rogerson, A. M., 1999: Transcritical flows in the coastal marine atmospheric boundary layer. J. Atmos. Sci., 56, 2761-2779.

— trapped disturbances in the marine atmospheric boundary layer. J. Atmos. Sci., 52, 2025-2040.

Samelson, R. M., 1992: Supercritical marine-layer flow along a smoothly varyiong coastline. J. Atmos. Sci., 49, 1571-1584.

_ 1999: The vertical structure of linear coastal-trapped disturbances. Mon. Wea. Rev., 127, 201-213.

— trapped disturbance. Mon. Wea. Rev., 124, 1853-1863.

Skamarock, W. C., J. B. Klemp, and R. Rotunno, 1996: The diffraction of Kelvin waves and bores at coastal bends. J. Atmos. Sci., 53, 1327-1337.

$\longrightarrow$, R. Rotunno, and J. B. Klemp, 1999: Models of coastally trapped disturbances. J. Atmos. Sci., 56, 3349-3365.

Sopko, S., 1998: Observation and analysis of coastally trapped wind reversals. M.S. thesis, Naval Postgraduate School, 146 pp. [Available from Naval Postgraduate School, 589 Dyer Rd., Monterey, CA 93943-5114.]

Thompson, W. T., and J. M. Bane, 1998: Modeling and observations of coastally trapped wind reversals. Preprints, Second Conf. on Coastal Atmospheric and Oceanic Prediction and Processes, Phoenix, AZ, Amer. Meteor. Soc., 194-201. , T. Haack, J. D. Doyle, and S. D. Burk, 1997: A nonhydrostatic mesoscale simulation of the 10-11 June 1994 coastally trapped wind reversal. Mon. Wea. Rev., 125, 3211-3230.

Winant, C., C. Dorman, C. Friehe, and R. Beardsley, 1988: The marine layer off northern California: An example of supercritical channel flow. J. Atmos. Sci., 45, 3588-3605.

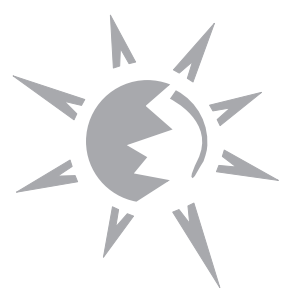

